University of Nebraska - Lincoln

DigitalCommons@University of Nebraska - Lincoln

Industrial and Management Systems

Engineering -- Dissertations and Student

Research

Industrial and Management Systems

Engineering

$12-2-2010$

\title{
DESIGN OF ASSEMBLY LINES WITH THE CONCURRENT CONSIDERATION OF PRODUCTIVITY AND UPPER EXTREMITY MUSCULOSKELETAL DISORDERS USING LINEAR MODELS
}

Zhan Xu

University of Nebraska-Lincoln, zhan.xu@huskers.unl.edu

Follow this and additional works at: https://digitalcommons.unl.edu/imsediss

Part of the Ergonomics Commons, and the Operational Research Commons

Xu, Zhan, "DESIGN OF ASSEMBLY LINES WITH THE CONCURRENT CONSIDERATION OF PRODUCTIVITY AND UPPER EXTREMITY MUSCULOSKELETAL DISORDERS USING LINEAR MODELS" (2010). Industrial and Management Systems Engineering -- Dissertations and Student Research. 12.

https://digitalcommons.unl.edu/imsediss/12

This Article is brought to you for free and open access by the Industrial and Management Systems Engineering at DigitalCommons@University of Nebraska - Lincoln. It has been accepted for inclusion in Industrial and Management Systems Engineering -- Dissertations and Student Research by an authorized administrator of DigitalCommons@University of Nebraska - Lincoln. 
DESIGN OF ASSEMBLY LINES

WITH THE CONCURRENT CONSIDERATION OF PRODUCTIVITY

AND UPPER EXTREMITY MUSCULOSKELETAL DISORDERS

USING LINEAR MODELS

by

Zhan Xu

A THESIS

Presented to the Faculty of

The Graduate College at the University of Nebraska

In Partial Fulfillment of Requirements

For the Degree of Master of Science

Major: Industrial and Management Systems Engineering

Under the Supervision of Professor Jeonghan Ko

Lincoln, Nebraska

December, 2010 


\title{
DESIGN OF ASSEMBLY LINES \\ WITH THE CONCURRENT CONSIDERATION OF PRODUCTIVITY AND UPPER EXTREMITY MUSCULOSKELETAL DISORDERS \\ USING LINEAR MODELS
}

\author{
Zhan Xu, M.S. \\ University of Nebraska, 2010
}

Adviser: Jeonghan Ko

The productivity of assembly lines is considerably affected by the health condition of assembly workers, and work-related musculoskeletal disorders (WMSDs) are common occupational diseases among assembly workers due to repetitive motions or heavy working loads. The conventional approaches to decreasing WMSD risks in the assembly lines include slowing the work-pace or applying job rotations. These adjustments usually focus on individual assembly workers at the station level but not the work allocation among the workers at the whole assembly line level, and thus may decrease the line productivity. To avoid these negative effects, some research started considering ergonomic characteristics at the line level, such as balancing ergonomic burdens by proper work assignment among workers. These previous studies incorporated physical grip demands or processing time overload into non-linear assembly line design problems, and used heuristic solution methods.

This paper presents a methodology that explicitly integrates ergonomic measures for upper extremities into linear assembly line design problems. As the ergonomic measures, 
this research considers a guideline of Threshold Limit Value (TLV) from American Conference of Industrial Hygienists. Linear models are developed to link work-worker assignment to the measures of hand activity and hand-arm vibration. As productivity measures, conventional assembly line design criteria are considered, such as cycle time and the number of workers. These linear models allow ergonomic and productivity measures to be integrated as a mixed-integer programming model for assembly line design. In addition, these linearization methods can be generalized in order to incorporate ergonomic measures in tabulated forms into assembly line design problems.

The analysis of the result shows the new model can effectively control the exposure levels in the upper extremity by proper work assignment compared to the conventional approaches, and does not decrease production rates considerably. This research also shows the potential to reduce the need of numerous task adjustments after assembly line design in traditional trial-and-error based assembly task adjustment. 


\section{ACKNOWLEDGEMENTS}

I would like to express my sincerest appreciation to Dr. Jeonghan Ko for his support and continuous guidance throughout my graduate study and research at the University of Nebraska-Lincoln. His suggestions and commitment have been a great source of inspiration for my research, as well as my personal life.

Also, I cannot help but thank my committee members, Dr. Michael Riley and Dr. David Cochran, for their suggestions and contribution. They were source of inspiration and priceless knowledge.

Special thanks are to my fellow students, Ehsan Nazarian, Yang Youngie, Yin Guo and Gang Hao, in the research group for sharing ideas and knowledge. They were nothing but wonderful friends.

Lastly, I must thank my parents and grandparents who believed in me from the start and kept on believing. 


\section{TABLE OF CONTENTS}

Abstract .. $\mathrm{i}$

Acknowledgements. . iii

Table of Contents. iv

List of Figures. .vi

List of Tables. viii

Chapter 1 Introduction. .1

1.1 Task Assignment and Work-related Musculoskeletal Disorders in Assembly Line Design. 1

1.2 Demand for More Efficient Methods to Combine Ergonomic Measures and Task Assignment for Assembly Line Design. . .3

1.3 Research Objective and Methodology Overview..............................4

1.4 Research Contributions........................................................

1.5 Thesis Organization....................................................7

1.6 Nomenclature................................................................

Chapter 2 Literature Review and Research Background...........................12

2.1 Assembly Line Design Problem.......................................12

2.2 Upper Extremity Assessment Tools....................................14

2.3 Measuring Exertion Frequency, Duty Cycle, Peak Force and Vibration

Acceleration.........................................................17

2.4 The Influence of Work Organization and Job Stress........................20 
Chapter 3 The Relation of Task Assignment to Exertion Frequency, Duty Cycle, Normalized Peak Force, Vibration Acceleration and Vibration Duration. 22

3.1 Determination of Hand Activity and Peak Force Measures by Task Assignment 22

3.2 Determination of Hand-arm Vibration Measures by Task Assignment. ... 25

Chapter 4 Mathematical Models of Assembly Line Design with the Linearized Hand Activity and Hand-Arm Vibration Constraints

4.1 Assumptions 28

4.2 Linear Formulas on Hand Activity and Hand-arm Vibration. 32

4.3 Optimization Model 37

Chapter 5 Numerical Experiments and Discussion. ... 41

5.1 Manufacturing Task Description and Parameter Estimation. .41

5.2 Results from Different Combinations of Ergonomic Constraints. .46

Chapter 6 Conclusions and Recommendations 52

References.... 54

Appendix A The Procedures for Calculating Frequency Weighted Acceleration......A1

Appendix B Results of LBMC, LBMCH, LBMCV and LBMCHV ................. B1

Appendix C The Computer Program of the Optimization............................................

Appendix D Solution PooL................................................ D1 


\section{LIST OF FIGURES}

Figure 1.1 Cost analysis by occupational injury and illness types.................. 2

Figure 1.2 The structure of the research......................................... 6

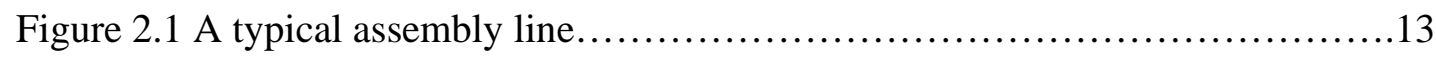

Figure 2.2 Hand activity level $(0-10)$ can be rated using the guideline...............15

Figure 2.3 Scale for rating Peak Hand Force..................................18

Figure 2.4 Biodynamic and basicentric coordinate systems for the hand, showing the directions of the acceleration components............................... 20

Figure 3.1 The TLVs based on HAL and NPF. The dashed line is the AL line, and

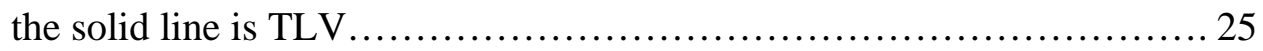

Figure 4.1 The relation between task assignment, task information, cycle time and

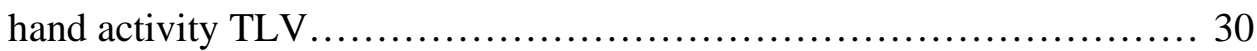

Figure 4.2 Structural diagram of relation between task assignment, task information, cycle time and hand-arm vibration TLV ..................................... 31

Figure 5.1 The task description and precedence of assembly tasks with vibration profiles.

Figure 5.2 The accelerations and the coordinate figures of the two screwdrivers.

Adapted from (Radwin and Armstrong 1985, 211-219)................. 45

Figure 5.3 Results from different constraint combinations.......................47

Figure 5.4 HAL TLV of LBMC, LBMCH, LBMCV and LBMCHV ................ 50

Figure A.1 One-third octave band spectra for the $3.4 \mathrm{~cm}$ diameter automatic shut-off screwdriver.... 
Figure A.2 One-third octave band spectra for the $2.5 \mathrm{~cm}$ diameter clutch screwdriver in the slippage of the clutch condition................... A2 


\section{LIST OF TABLES}

Table 2.1 Versions of SALBP

Table 2.2 Hand activity level (0-10) is rated based on exertion frequency and duty cycle (\% of work cycle where a worker's force is greater than $5 \%$ of the maximum)

Table 3.1 TLVs for exposure of the hand to vibration in either X, Y, Z Axis. 27

Table 4.1 Reference table of HAL with $m=5$. 34

Table 4.2 The conversion of intermediate value $v_{s}^{h}$ to HAL............................

Table 4.3 The set of ranges of exertion frequencies................................35

Table 4.4 The set of ranges of duty cycles......................................

Table 4.5 The conversion of daily vibration duration to acceleration TLV............ 36

Table 5.1 Data of exertion number, cycle time and NPF ....................... 43

Table 5.2 Male power grip strengths in Newton (N)........................ 44

Table 5.3 Acronyms for the line balancing models............................ 46

Table 5.4 Relative value of ergo measures compared to LBMC case................ 50

Table 5.5 Vibration results................................................ 51

Table A.1 Frequency-weighting factors for hand-arm vibration................... A1

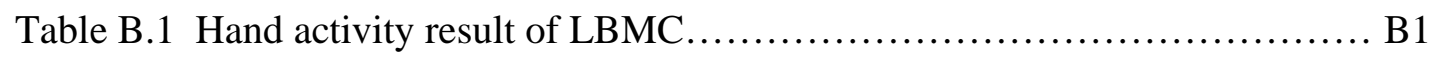

Table B.2 Hand activity result of LBMCH................................ B2

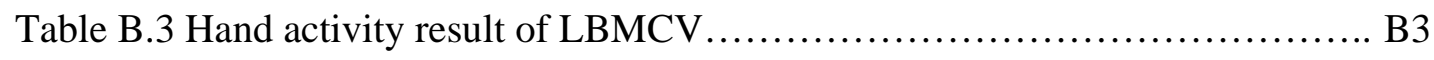

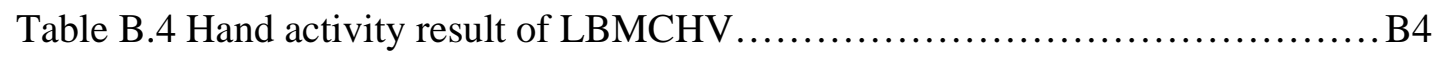

Table B.5 Detailed vibration results........................................ B5 
Table D.1 Part of solution pool calculating by ILOG CPLEX 11.2.0 .............. D1 


\section{CHAPTER 1}

\section{INTRODUCTION}

Chapter 1 is the overview of this research. This chapter introduces task assignment in assembly line design and work-related musculoskeletal disorders problems. The chapter also describes the need for new methodologies to combine ergonomic measures and task assignment models. This chapter also presents the objectives, methodologies, and contributions of this research. The nomenclature of this research is also included.

\subsection{Task Assignment and Work-related Musculoskeletal Disorders in Assembly Line Design}

An assembly line consists of a series of work stations, in which particular operations (set of assembly tasks) are executed repeatedly (Carnahan, Norman and Redfern 2001, 875887). Here, each “assembly task” represents a basic indivisible work element for assembling products. Note that this task definition is different from those in the ergonomic literature. In the ergonomic literature a task often represents the duty of a worker: the set of all operations a worker should perform in a work station. The advantages of the assembly line include: (1) improving product quality and (2) accelerating working speed (Rekiek and Delchambre 2006). The conventional assembly line design focuses on line efficiency such as maximizing productivity or minimizing the number of work stations.

Task assignment is one of the most important decisions in the assembly line design. The assignment of tasks to work stations determines line characteristics such as cycle time, 
idle time and number of work stations. Furthermore, task assignment determines the level of the physical exposure of each worker, which may cause occupational disease.

Work-related musculoskeletal disorder (WMSD) problems are the typical occupational diseases among assembly line workers, and are one of the most common lost-time injuries. WMSD problems include low-back pain, strain injuries and vibration-induced white finger (VWF) (Health and Safety Executive ). WMSDs cause on average approximately $43 \%$ of the total annual lost-time (Ontario Ministry of Labour ). Moreover, WMSDs are considered as the most costly occupational problems. They accounted for over 28\% of workplace safety and insurance board costs in Canada (Figure 1.1), including compensation and medical costs. A study shows WMSDs are caused by several work place factors such as repetitive motion, forceful exertions, vibration and awkward postures (Punnett and Wegman 2004, 13-23).

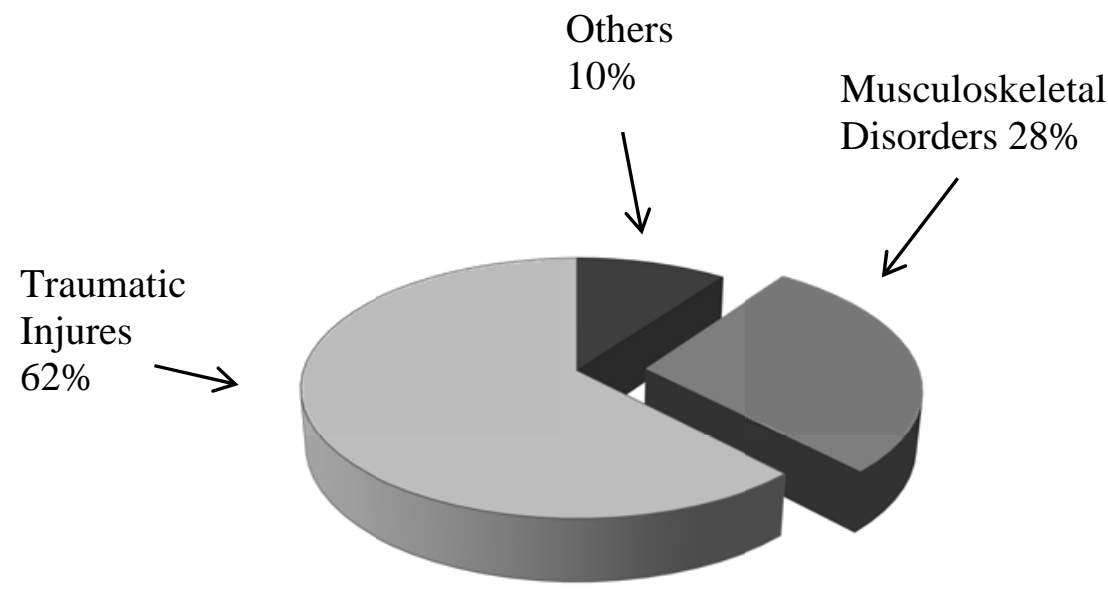

Figure 1.1 Cost analysis by occupational injury and illness types in Canada (Peter Vi 2007) 


\subsection{Demand for More Efficient Methods to Combine Ergonomic Measures and Task Assignment for Assembly Line Design}

The conventional approaches for preventing assembly workers from WMSDs can be classified into two categories. The first category is to improve working conditions in order to decrease the physical workload demands. These approaches include adjusting working tables, applying ergonomically designed tools, slowing work pace (Escorpizo and Moore 2007, 609-615), and changing the shape or size of products (Kedlaya and Kim 2007). In general, awkward postures can be reduced by improved work place design and layout, and excessive force can be reduced by a mechanical assist or improved tools. Vibrations can be dampened by absorbing material or strengthening structures. The reduction of human repetition typically is the most difficult for an ergonomist to solve, because repetition is a primary component for reducing cost. Replacing the human with some forms of automation may be the only available choice for reducing human repetition but automation may be economically infeasible. In addition, slowing work pace will decrease the productivity, and changing the product shape may affect the function of products.

The second category is to vary the tasks of workers. Diversifying tasks of workers may prevent using the same parts of a human body repeatedly (Kedlaya and Kim 2007), and relieve psychological stress affecting WMSD risks (Carayon, Smith and Haims 1999, 644). These approaches include work organization methodologies such as work rotation, work enlargement, and working teams. However, some research shows task shifting may increase WMSDs (Spallek et al. 2010, 6), because workers may not learn fast enough how to protect themselves from occupational injuries in new jobs. In addition, shifting 
jobs may prolong the job preparation time in assembly lines, thus decreasing productivity. The specific repetitions are essentially spread out among more employees which may in the long run be detrimental to additional workers.

Moreover, these procedures of ergonomic adjustment may not be coordinated well with assembly line design. Assembly task assignment and ergonomic evaluations are often carried out separately in assembly line design and planning. Although some previous studies considered the ergonomic characteristics for the line design, these studies used non-linear forms of ergonomic measures. This non-linearity led to difficulties in using efficient linear assembly line design formulations and the use of heuristic solution methods. This lack of efficient methodology to consider ergonomics in assembly line design usually leads to numerous trial-and-error based task adjustments after initial task assignment. This situation needs improvement.

\subsection{Research Objective and Methodology Overview}

The long-term goal of this research is to help reduce the WMSDs in upper-body extremities among assembly workers by developing an assembly line design methodology integrating productivity and ergonomic considerations. The objectives are:

1. To develop a methodology that incorporates hand activity and hand-arm vibration measures into the task assignment models in assembly line design. In particular, this research builds linear functions integrating the exertion frequency, duty cycle, normalized peak force (NPF), vibration acceleration and vibration duration measures into the linear task assignment model. These linear models are integrated for assembly line design by using mixed-integer programming (MIP). 
2. To demonstrate the feasibility of the modeling methodology to identify the impact of the ergonomic consideration on assembly line design in terms of task assignment, and examine the trade-offs between productivity and ergonomic conditions. The models developed in this research will help control WMSD risks with reducing possible negative impact on line efficiency.

To achieve the research objectives, this research was conducted as follows, and the overall structure is shown in Figure 1.2. First, the physical exposure in an assembly line for this research consists of five ergonomic characteristics: peak force, number of exertions, duty time, equivalent accelerations of vibration and vibration duration. A guideline for industrial hygienists concerning physical exposures of operators (ACGIH 2008) was used for building the equations for the ergonomic characteristics. These numerical ergonomic representations mainly focus on upper body extremities.

Second, these ergonomic formulas are created as linear functions of task assignment. These linear formulas allow the easier integration of the ergonomic measures into linear assembly line design models.

Third, an assembly line design model is built by incorporating the linearized ergonomic measures and conventional assembly line characteristics into an MIP model. The conventional assembly line characteristics include task precedence, cycle time and the number of work stations. The objective function of the MIP model is to minimize the number of workers in the assembly line.

Fourth, through numerical experiments, this research analyzes the effect of different ergonomic considerations by solving the MIP model with different combinations of 
ergonomic constraints. This analysis demonstrates the effectiveness of the new integrated approach compared to a conventional assembly line model without ergonomic considerations.

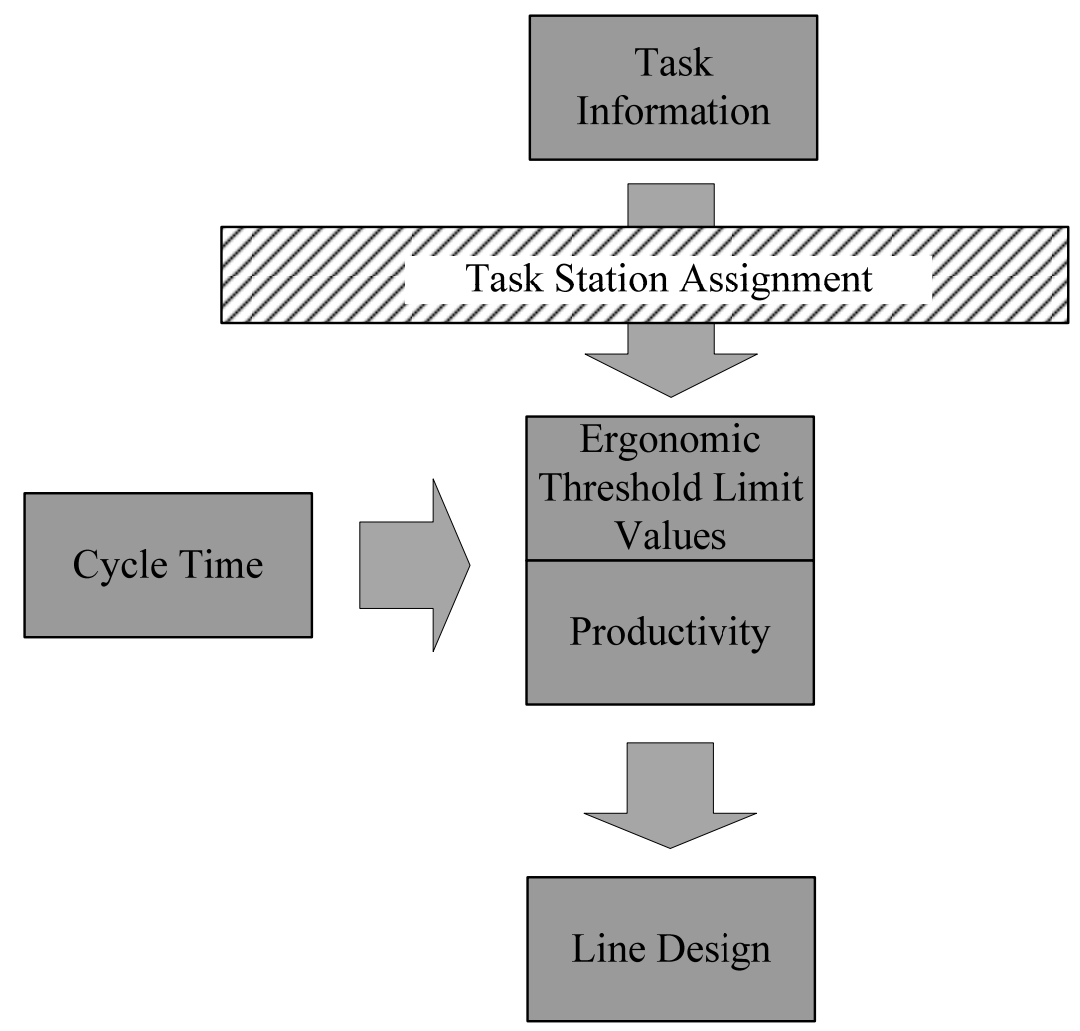

Figure 1.2 The structure of the research

\subsection{Research Contributions}

The new approach in this paper has the potential to improve the conventional practice by which we design an assembly line and reduce ergonomic risks. Traditionally, assembly task assignment and ergonomic evaluations are often conducted separately. Only a few previous studies illustrated physical demands and task processing time can be incorporated into task assignment models using heuristic solution methods (Choi 2009, 
395-400)(Carnahan, Norman and Redfern 2001, 875-887). Compared to these previous studies, this research develops more explicit integration of task assignment and ergonomic measures using linearized formulations. The linearity of these formulas enables us not only to integrate ergonomic task characteristics directly but also use efficient solution methods to optimize assembly line design, in particular for upper body extremities. Moreover, these linearization methods can generalize ergonomic measures in table listed forms and incorporate them into other assembly line design problems.

The linear models developed in this research help reduce WMSD risks. The ergonomic measures incorporated with task assignment can be used to limit the peak force and vibration exposure levels of upper body extremities in all stations in an assembly line. The developed methodology can be extended to incorporate a variety of ergonomic characteristics of assembly tasks. This feature provides flexibility to consider other ergonomic constraints during assembly line design. Hence, this research will help prevent WMSD risks among assembly workers.

\subsection{Thesis Organization}

The remainder of this chapter lists the mathematical symbols used in this paper. Chapter 2 consists of literature reviews. Chapter 3 discusses the relationship of task assignment to hand activity and vibration levels. Chapter 4 describes the mathematical models of assembly line design with the consideration of ergonomic measures and production rates. Chapter 5 presents the comparison of the conventional and new assembly line design models using numerical examples. Chapter 6 summarizes and concludes the thesis. 


\subsection{Nomenclature}

The mathematical symbols used in this study are introduced as follows.

Indexes

$$
\begin{aligned}
f & =\text { The one-third octave band number } \\
h & =\text { Hand number } h=1,2 \\
i, j & =\text { Manufacturing task } \\
o & =\text { The direction of vibration, } o=\mathrm{X}, \mathrm{Y}, \mathrm{Z} \\
p & =\text { The range number of } e f_{s}^{h} \\
q & =\text { The range number of } d c_{s}^{h} \\
s & =\text { Worker or station; } s=1,2, \ldots, M \\
u & =\text { One dimensional cell value for the table of hand activity level }
\end{aligned}
$$

Parameters

$$
\begin{aligned}
& C N=\text { The maximum Column Number } \\
& C T=\text { The cycle time of the assembly line } \\
& H T_{u}=\text { The HAL value corresponding to } u
\end{aligned}
$$




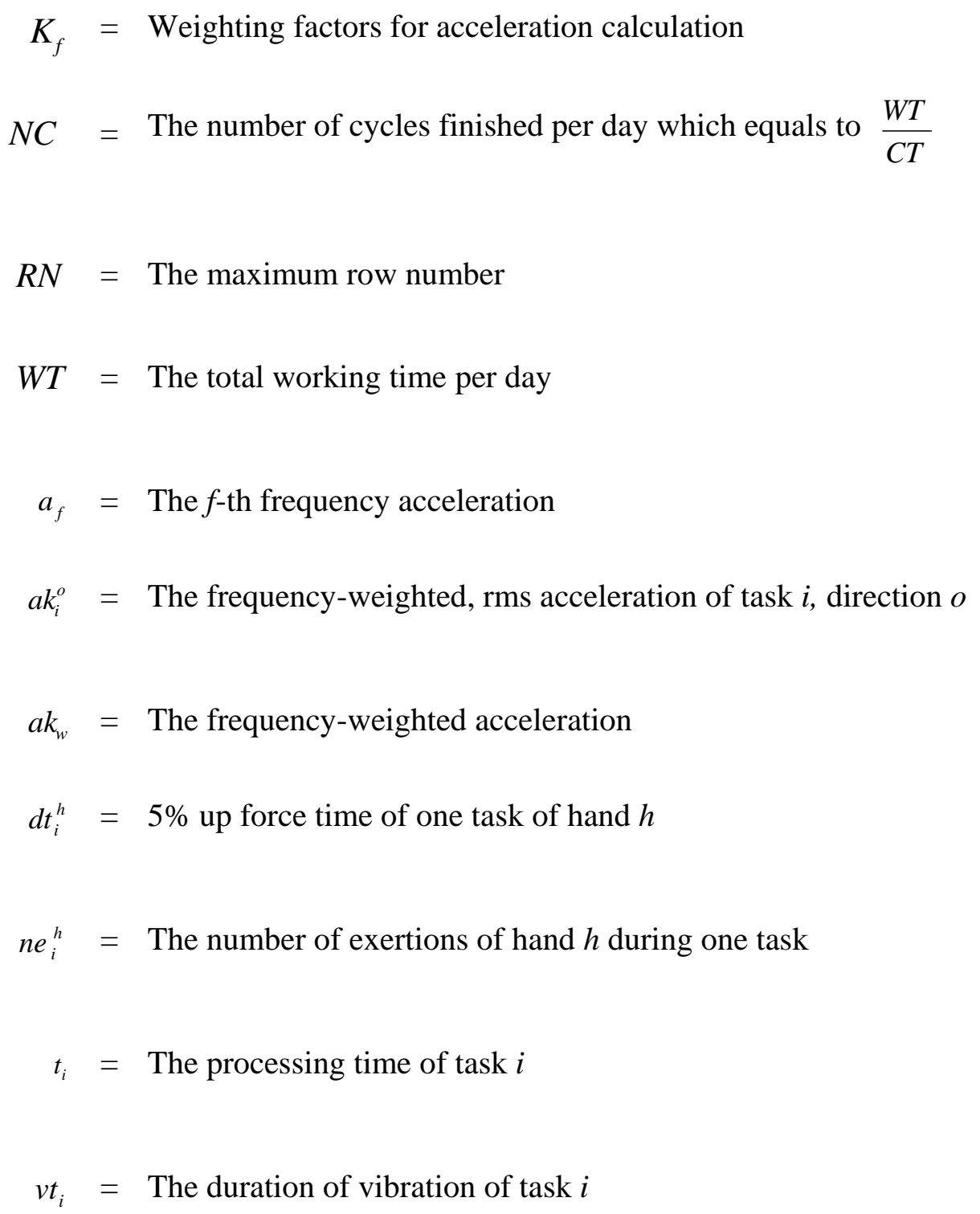

Variables

$\mathbf{1}\left(E F_{p}, e f_{s}^{h}\right)=$ The indicator variable; one if $e f_{s}^{h}$ belongs to $E F_{p}$, zero otherwise

$\mathbf{1}\left(D C_{q}, d c_{s}^{h}\right)=$ The indicator variable; one if $d c_{s}^{h}$ belongs to $D C_{q}$, zero 


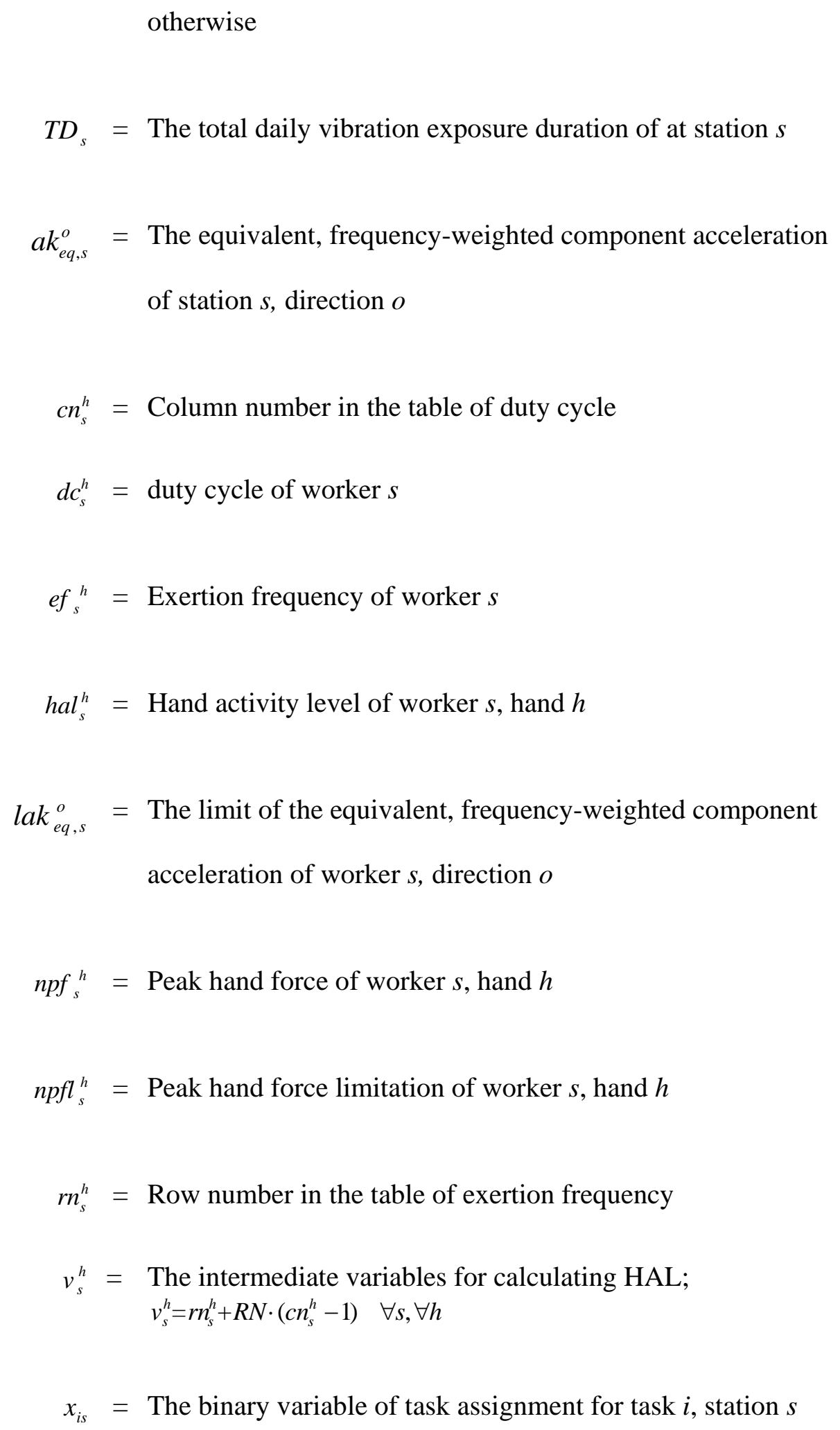


$y_{s, u}^{h}=$ The binary variable of hand activity level of each hand of each worker in each station

$z=$ Objective function value 


\section{CHAPTER 2}

\section{LITERATURE REVIEW AND RESEARCH BACKGROUND}

This chapter introduces the previous studies and background on assembly line design and ergonomics. The principles of assembly line design are examined and summarized. Ergonomic assessment of upper extremity and the approach of measuring some ergonomic measures are also introduced. The relationship between work organization and WMSDs is presented. The recent research on assembly line model with the consideration of ergonomics is also presented.

\subsection{Assembly Line Design Problem}

Assembly line design or balancing problem (ALBP) occurs when building or reconfiguring an assembly line. The main focus of ALBP is how to distribute the entire workload to the work stations of an assembly line (Becker and Scholl 2006, 694-715). Figure 2.1 shows a typical assembly line. An assignable portion of the total work load is named as a task (Scholl 1999). The operating time of one task is considered as task time. The total allowable operating time of each work station is cycle time. The sum of task times of each work station is less than or equal to the cycle time. The number of work stations could be given or depend on the cycle time and other manufacturing limitations.

The objectives of ALBP are to minimize cycle time, reduce number of workstations, or level manufacturing workload. To achieve these goals, mathematic models are widely applied in ALBP. The first mathematical formalization of ALBP was developed by (Salveson 1955, 18-25). In a review paper (Baybars 1986, 909-932), simple assembly 
line balancing problem (SALBP) was used to represent the basic problems with numerous simplifying assumptions.

Flow of Material

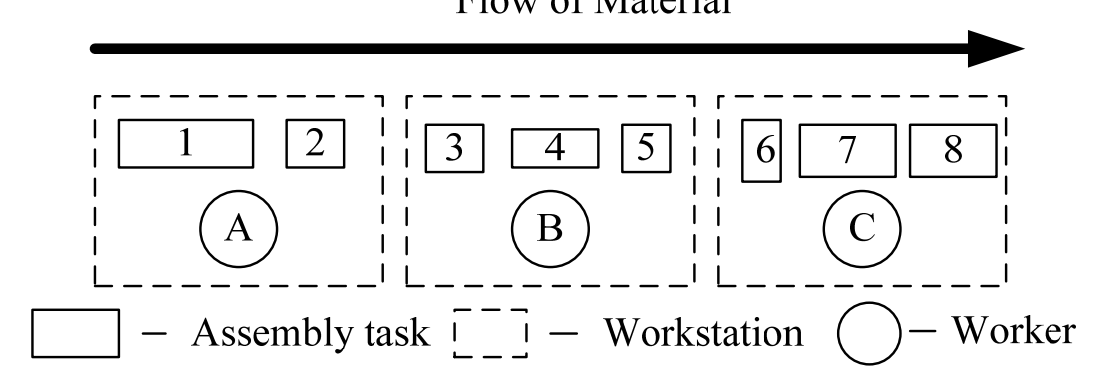

Figure 2.1 A typical assembly line (Carnahan, Norman and Redfern 2001, 875-887)

SALBP was classified into four categories by the different objectives: see Table 2.1.

Feasibility problems (SALBP-F) focus on minimizing the idle time of each work station (Moodie and Young 1965, 23-29). The goals of line efficiency problems (SALBP-E) are minimizing the sum of total idle times given cycle time and the number of work stations (Rekiek and Delchambre 2006). The goal of work station problem (SALBP-1) is minimizing the number of work stations with given cycle time. On the contrary, the aim of cycle time problem (SALBP-2) is minimizing the cycle time given the number of work stations (Scholl and Becker 2006, 666-693).

Table 2.1 Versions of SALBP (Becker and Scholl 2006, 694-715)

\begin{tabular}{ccc}
\hline & \multicolumn{2}{c}{ Cycle Time } \\
\cline { 2 - 3 } Number of Stations & Given & Minimize \\
\hline Given & SALBP-F & SALBP-2 \\
Minimize & SALBP-1 & SALBP-E \\
\hline
\end{tabular}


Linear programming (LP) and mixed-integer linear programming (MIP) are widely used in assembly line models because of their usability and analyzability. Salverson (1955, 1825) creates a linear model that considers all possibilities of work station assignments. The model he presented can result in split tasks. However, the infeasible solution is possible, because none of combination of station assignments can satisfy the requirements such as the limitation of cycle time (Salveson 1955, 18-25). Bowman first developed "nondivisibility" constraints by using integer programming to present LP formulation. White modifies Bowman's model, and defines the binary decision variable to stand for the assignments of tasks. White also builds the basic SALBP-1 models which encompass the constraints of "cost” for each station and the precedence of tasks (White 1961, 274-276).

\subsection{Upper Extremity Assessment Tools}

American Conference of Industrial Hygienists (ACGIH) is an association which is committed to prevent workers from occupational diseases. Hand activity levels (HALs) are introduced by the ACGIH for mono-task jobs performed longer than 4 hours per day. “Task” which represents duty in ergonomics is different from "task” representing the basic indivisible element in ALBP. Workers who repeatedly perform the same exertions every work cycle are considered as acting “mono-task” by definition. HAL are offered for assessing the WMSD risks in such cases. The scale for HAL was proposed by (Latko et al. 1997, 278-285), and this scale range is from 0 to 10 . In this particular scale, 0 represents “completely idle” and 10 stands for the greatest level of “continuous exertion”. HAL is not only a function of frequency but also a function of work speed. There are two ways to determine HAL: 
1. HAL can be obtained from Figure 2.2, which is based on the frequency of hand exertions, the idle time of hand exertions and the speed of motions and

2. HAL can be calculated from Table 2.2, which contains the exertion frequency and duty cycle.

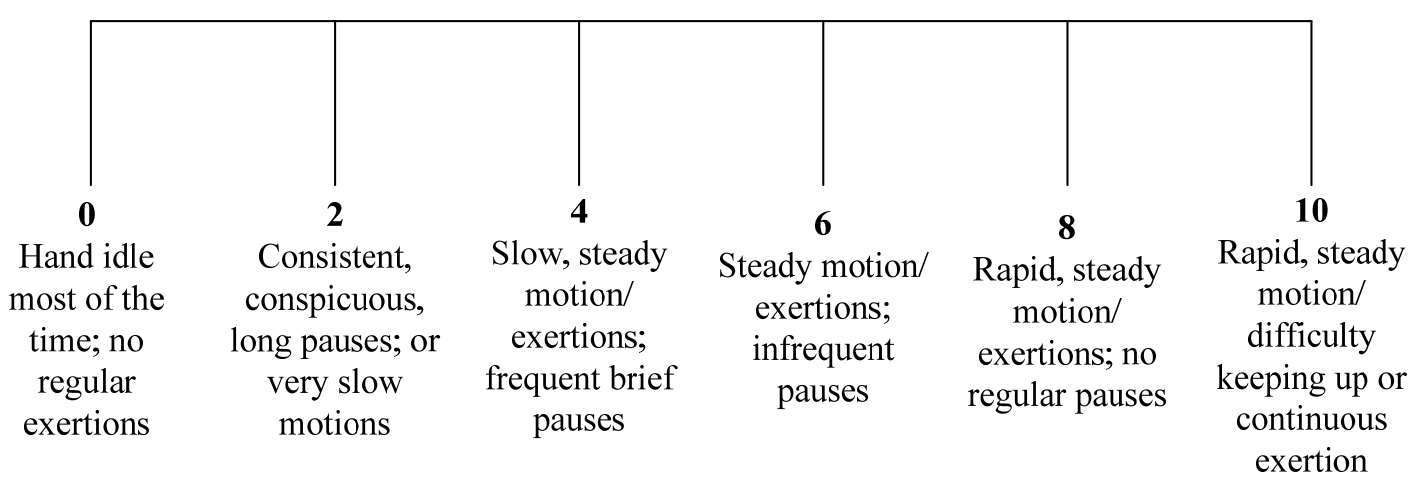

Figure 2.2 Hand activity level (0-10) can be rated using the guideline (ACGIH 2008)

Table 2.2 Hand activity level (0-10) is rated based on exertion frequency and duty cycle (\% of work cycle where a worker's force is greater than $5 \%$ of the maximum) (ACGIH 2008)

\begin{tabular}{ccccccc}
\hline & & \multicolumn{5}{c}{ Duty Cycle (\%) } \\
$\begin{array}{c}\text { Frequency } \\
\text { (exertion/s) }\end{array}$ & $\begin{array}{c}\text { Period } \\
\text { (s/exertion) }\end{array}$ & $0-20$ & $20-40$ & $40-60$ & $60-80$ & $80-100$ \\
\hline 0.125 & 8.0 & 1 & 1 & - & - & - \\
0.25 & 4.0 & 2 & 2 & 3 & - & - \\
0.5 & 2.0 & 3 & 4 & 5 & 5 & 6 \\
1.0 & 1.0 & 4 & 5 & 5 & 6 & 7 \\
2.0 & 0.5 & - & 5 & 6 & 7 & 8 \\
\hline
\end{tabular}


Threshold Limit Value (TLV) is the guideline used by some industrial hygienists in trying to prevent occupational hazards (ACGIH 2008). By the applications of TLVs, most TLV methods fall into two categories. TLVs for physical agents are used in determining the exposure level of vibration, radiation and heat/cold stress, in which operators can work for certain time day after day nearly without suffering occupational diseases during and after career (ACGIH ). Similar to TLVs for physical characteristics, TLVs for chemical substances help decide the safe levels of exposure to chemical substances (ACGIH ). “Threshold limit values for chemical substances and physical agents \& biological exposure indices” (ACGIH ) are recommended. HAL and normalized peak force (NPF) are the two dependent variables used in the ACGIH HAL TLV. Hand-arm (segmental) vibration is also a factor affecting WMSD risks, and TLV of vibration is introduced by ACGIH. Table 3.1 in Chapter 3 shows the TLVs that workers may finish tasks repeatedly without reaching the Stage 1 of the Stockholm Workshop Classification System for VWF (ACGIH 2008). Besides applying the TLVs, workers who perform vibration tasks should use anti-vibration tools, wear anti-vibration gloves, and accept proper work practice and medical surveillance.

The cumulative trauma disorder (CTD) risk assessment model for the upper extremities was developed by (Seth, Lee Weston and Freivalds 1999, 281-291). Occupational repetitive actions index (OCRA) was developed by (Occhipinti 1998, 1290-1311). The rapid entire body assessment (REBA) was designed for reducing WMSDs by (Hignett and McAtamney 2000, 201-206). McAtamney and Corlett studied and evaluated the validity and reliability of the assessment tool of rapid upper limb assessment (RULA) in 1993 (McAtamney and Nigel Corlett 1993, 91-99). 


\subsection{Measuring Exertion Frequency, Duty Cycle, Peak Force and Vibration Acceleration}

Exertion frequency, duty cycle, normalized peak force (NPF) and vibration acceleration are measures related to WMSDs (ACGIH 2008, Armstrong 2008, 3-4). Exertion frequency is found by dividing the number of exertions by the cycle time, and exertions are determined from analyzing the work elements. Duty cycle is the percentage of duty time during one work cycle. Duty time is obtained based on the perceived percentage maximum voluntary contraction. By definition, only the period where a worker exerts force that is greater than $5 \%$ of the maximum is counted as duty time (Armstrong 2008, 3-4).

Visual analogue scales are widely applied in obtaining perceived exertion (Latko et al. 1997, 278-285) as in Figure 2.3. A visual analogue scale usually consists of a ten centimeter horizontal line on a scale from 0 to 10 . This horizontal line is labeled as $0,2,4$, 6,8 , and 10 correspondingly from the left end to the right end. The left end stands for "no effort" and the right end stands for "greatest effort imaginable”. The job is assessed by measuring the distance from the left end to a certain mark made by workers. This mark is made through drawing a horizontal line on the visual analogue scale that most closely to the peak effort connected to a worker's job. The visual analogue scale only focuses on individual's rating, thus this individual rating force need to be normalized by selecting suitable strength value.

For example, suppose the right hand grip strength requirement of a task is 3 on the scale and a 50th percentile male office worker right hand force equals $463.5 \mathrm{~N}$. Also suppose 
this subject's right hand maximum grip force is $400 \mathrm{~N}$. Then, the 50th percentile male normalized hand force equals $\frac{3 \times 400}{463.5}=2.6$.

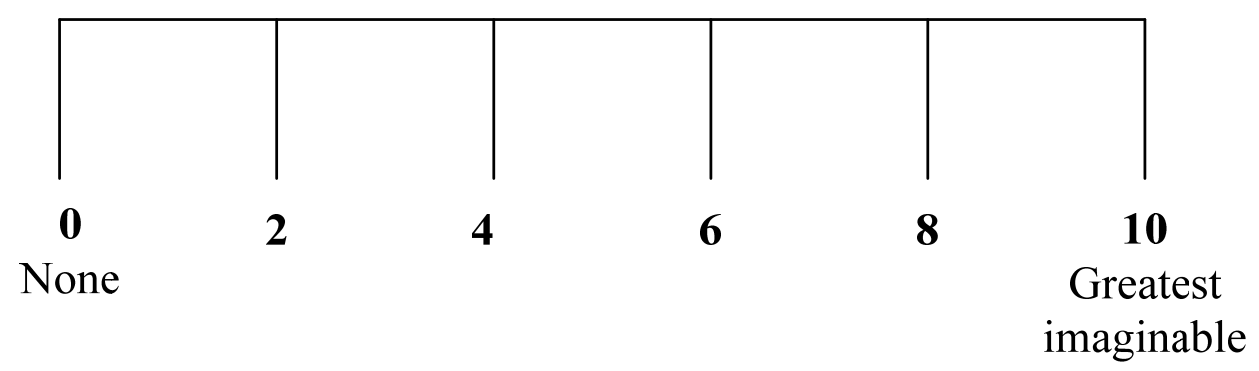

Figure 2.3 Scale for rating peak hand force (Latko et al. 1997, 278-285)

Vibration accelerations are measured by three accelerometers in three directions shown in Figure 2.4. All accelerations are weighted by frequency according to ISO 5349 and ANSI S3.34-1986 (Appendix A).

Hand-tool vibration can cause cumulative trauma. For example, VWF is induced in the vibration frequency range of 50-100 Hz because of the decreasing of blood flow to hands (Helander 2006). Vibration acceleration is adopted to represent the severity of vibration in many standards (Griffin 1996). According to the severity of vibration, the corresponding daily vibration exposure time is suggested by ACGIH, and shown in Table 3.1 (ACGIH 2008). This research considers the hand-arm vibration, and all vibration accelerations are frequency weighted based on Table A.1 from ISO 5349 (International Organization for Standardization). 
The measurement of vibration involves many practical issues. The tools for measuring vibration frequency and acceleration include amplifiers, accelerometers and recording equipment. The methods of installation accelerometers are various depending on different types of tactility. This research assumes that all accelerometers are attached on the handles, because workers’ hands directly contact with vibration surfaces (ISO 5349 (International Organization for Standardization). Amplifiers are used to boost the vibration signals. Therefore, investigators may unambiguously record the accelerations for wide frequency range. This feature is important for building octave band spectra that is the common figure representing vibration. Recording equipment could be some frequency-modulated (FM) tape recorders or digital recorders (Griffin 1996).

The grip force also affects vibration. Previous research shows the increase in grip force does not lead to the substantial increase in vibration acceleration (Pyykko et al. 1976, 8795). In this research, we assume workers exert the same grip force in the same assembly tasks, so that vibration acceleration will not change because of the fluctuation of grip force. 


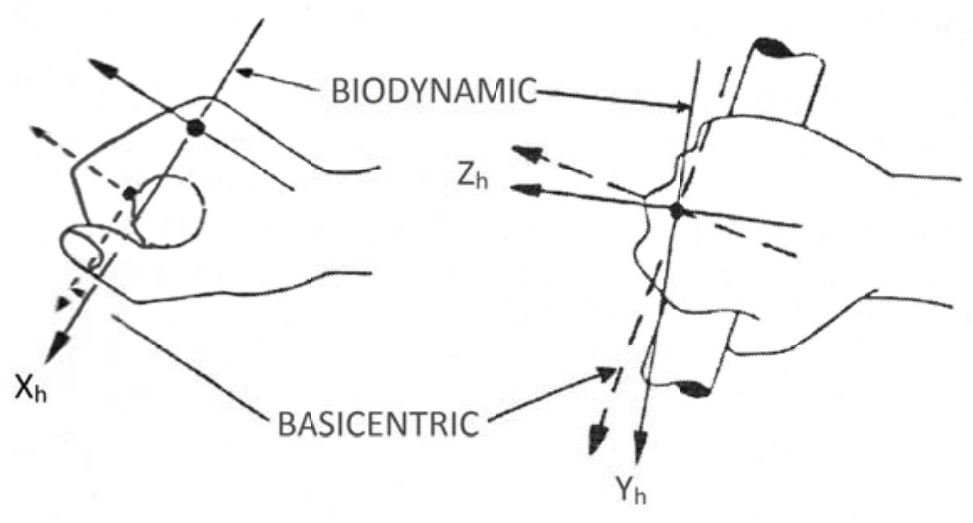

Figure 2.4 Biodynamic and basicentric coordinate systems for the hand, showing the directions of the acceleration components (ISO 5349 (International Organization for Standardization) and ANSI S3.34-1986 (American National Standards Institute))

\subsection{The Influence of Work Organization and Job Stress}

Recent studies have shown that work organization and job stress are related to WMSD risks (Carayon, Smith and Haims 1999, 644). Research conducted at University of Wisconsin-Madison has investigated the relationship between work organization and WMSDs (Carayon, Smith and Haims 1999, 644). Lim (1994) examines the role of psychological stress on negative musculoskeletal effects (Carayon, Smith and Haims 1999, 644). A framework of connecting the job-related factors that can affect both the stress and WMSDs was developed by (Smith and Sainfort 1989, 67-79). However, work organization does not always show positive effects. Spallek et al. (2010, 6) presented changing job tasks raises the WMSD risks due to the unfamiliarity of new tasks. 


\subsection{Assembly Line Models Considering Occupational Diseases}

Carnahan, Norman and Redfern (2001, 875-887) present three heuristic algorithms that integrate physical demand criterion into balancing assembly lines, and all algorithms are tested in the numerical experiments which include 100 assembly balancing problems. The result shows a genetic algorithm can solve this problem without impacting the assembly line configuration (Carnahan, Norman and Redfern 2001, 875-887). Choi (2009, 395-400) used goal programming to solve a model that considers physical workload and processing time together with diverse risk elements. The results demonstrated the model they applied was superior to the model that only concerns traditional ALBP in terms of reducing physical workload (Choi 2009, 395-400). Both research papers applied heuristic solution methods. 


\section{CHAPTER 3}

\section{THE RELATION OF TASK ASSIGNMENT TO EXERTION FREQUENCY, DUTY CYCLE, NORMALIZED PEAK FORCE, VIBRATION ACCELERATION AND VIBRATION DURATION}

This chapter describes how to incorporate task assignment and upper extremity ergonomic measures by equations.

\subsection{Determination of Hand Activity and Peak Force Measures by Task Assignment}

Task assignment strongly affects individual worker's ergonomic condition. Basically, task assignment is the procedure of dividing the workload needed for assembling one product into several elements and distributing them among work stations. Every task possesses ergonomic characteristics affecting the hand's exposure levels such as the number of exertions, duty time and peak force. Because a worker's job in an assembly station is usually a set of several indivisible tasks, different task assignment (different sets of tasks assigned to each worker) results in different number of exertions and duty times for each worker.

The relations of the exertion frequency and duty cycle to task assignment are formulated as linear Eqs. (1)-(2), respectively. In this research, it is assumed that one worker charges one work station's job, and does not share the job with other workers. Thus, a worker is equivalent to a station in terms of task assignment, and they are used interchangeably in this thesis. All tasks are performed in standing posture. 
$e f_{s}^{h}=\frac{\sum_{i=1}^{I} n e_{i}^{h} \cdot x_{i s}}{C T} \quad \forall s, \forall h$

$d c_{s}^{h}=\frac{\sum_{i=1}^{I} d t_{i}^{h} \cdot X_{i s}}{C T} \quad \forall s, \forall h$

Eq. (1) represents the exertion frequency at hand $h$ of worker $s$, defined as the number of exertions per time unit. Eq. (1) expresses the sum of the numbers of exertions of all tasks assigned to workers divided by the cycle time of the station. In the equation, $x_{i s}$ is the task-station assignment variable, $n e_{i}^{h}=$ the number of exertions of task $i$, hand $h, C T$ is the cycle time in the assembly line. Thus, $e f_{s}^{h}$ represents the exertion frequency in station $s$, hand $h$.

Eq. (2) represents the duty cycle at worker $s$ hand $h$, defined as the ratio of total time of duties in a work cycle. Eq. (2) expresses the total duty time of all tasks assigned to workers divided by the cycle time of the station. In the equation, $x_{i s}$ is again the taskstation assignment variable, $d t_{i}^{h}=$ the duty time of task $i$ hand $h, C T$ is the cycle time in the assembly line. Thus, $d c_{s}^{h}$ represents duty cycle in station $s$, hand $h$.

In these equations, number of exertion $\left(n e_{i}^{h}\right)$ represents the number of energy costing motions, and duty time $\left(d t_{i}^{h}\right)$ is the duration where the worker exerts more than $5 \%$ of the maximal force (ACGIH 2008). Both of them are measured based on single assembly task.

Peak force is also an important factor contributing to WMSD risks (Armstrong 2008, 3-4). A worker's maximal force performed in one repeated job is represented as peak force and 
usually normalized as a dimensionless measure to fit the general population (ACGIH 2009, 20). If tasks with large amount of exertions and heavy normalized peak force (NPF) are assigned to a worker, this worker’s WMSD risk could be considerably high.

The normalized peak force limit is related to the combined level of the exertion frequency and duty cycle (expressed as hand activity level at (Table 2.2)), and this relationship is explained below. In Figure 3.1, the horizontal axis represents the hand activity level (HAL) and the vertical axis the NPF. According to a variety of workers' strengths, an action limit (AL) is recommended as a safe bound. One expression of the AL was proposed as shown in Eq. (3) (Drinkaus et al. 2005, 263-281) and is shown as the dashed line in Figure 3.1. The combination of HAL and NPF levels should be below the AL line. Thus, NPF is restricted based on the HAL as shown in Eq. (4).

$$
\begin{aligned}
& n p f l_{s}^{h}=\frac{5}{9} h a l_{s}^{h}+5 \frac{5}{9} \quad \forall s, \forall h \\
& n p f l_{s}^{h} \geq x_{i s} \cdot n p f_{s}^{h} \quad \forall s, \forall i, \forall h
\end{aligned}
$$

where $n p f l_{s}^{h}=$ NPF limitation of station $s$ and hand $h, h a l_{s}^{h}=$ HAL value of worker $s$ and hand $h$, and $n p f_{s}^{h}=$ NPF value of worker $s$ and hand $h$. 


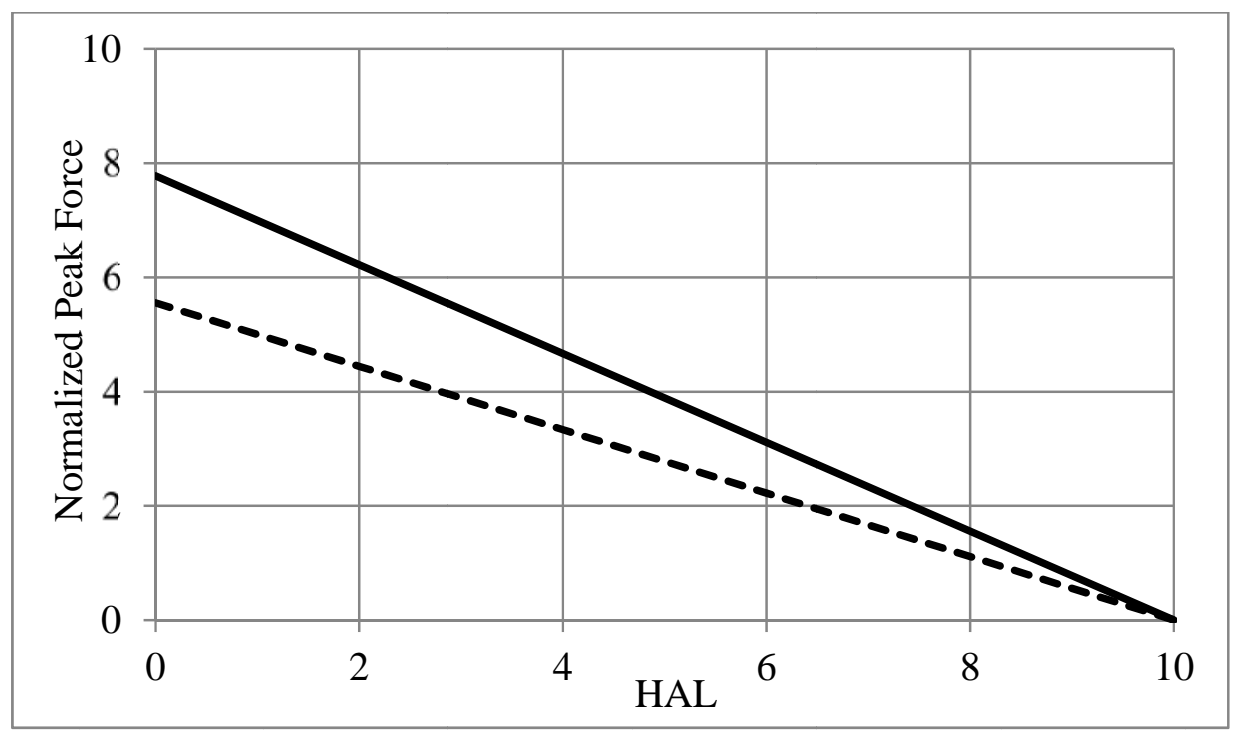

Figure 3.1 The TLVs based on HAL and NPF. The dashed line is the AL line, and the solid line is TLV (ACGIH 2008)

\subsection{Determination of Hand-arm Vibration Measures by Task Assignment}

Vibration duration and vibration equivalent acceleration are also related to upper extremity WMSDs. Assembly tasks often require using tools vibrating such as pneumatic screwdrivers and electric drills. These tools cause vibration in upper extremities and exposure to these vibration causes WMSDs.

The daily vibration duration and its relation to task assignment are expressed in Eq. (5).

$T D_{s}=\sum_{i}^{I} x_{i s} \cdot v t_{i} \cdot N C \quad \forall s$ 
Eq. (5) represents the sum of the vibration duration of all tasks. In the equation, $x_{i s}$ is the task-station assignment variable, $v t_{i}=$ the duration of vibration of task $i, N C$ is the number of work cycles per day in the assembly line, defined as the total daily working time divided by the cycle time. Thus, $T D_{s}$ represents the daily vibration duration in station $s$.

The frequency-weighted, equivalent, component acceleration of a set of tasks is expressed by Eq. (6), and the largest equivalent acceleration among three directions is considered as the dominant acceleration used to evaluate the vibration level (ACGIH 2008).

$a k_{e q, s}^{o}=\sqrt{\frac{\sum_{i}^{I}\left(a k_{i}^{o}\right)^{2} \cdot x_{i s} \cdot v t_{i} \cdot N C}{T D_{s}}} \forall s, \forall o$

where $a k_{e q, s}^{o}=$ the equivalent, frequency-weighted component acceleration of station $s$, direction $o, a k_{i}^{o}=$ the frequency-weighted, rms acceleration of task $i$, direction $o, T D_{s}=$ the total daily exposure duration of vibration of station $s$, and $N C=$ the number of work cycles a worker completes per day (ACGIH 2008). Note that Eq. (6) is not a linear function of task assignment. The linearization is addressed in Section 4.2.

Because the vibration data of each task are measured in the realistic task operation, the data usually include the impacts of grip forces on vibration. Also, the effect of static grip force on vibration is known not significant (Pyykko et al. 1976, 87-95). Thus, the TLVs of HAL and vibration acceleration can be evaluated independently. 
The vibration equivalent acceleration TLVs are shown in Table 3.1. TLV for acceleration is the limit of the largest acceleration in all three directions. Any equivalent vibration acceleration in the station should not exceed the TLV. TLVs vary by the daily vibration durations in the station as shown in Table 3.1.

Table 3.1 TLVs for exposure of the hand to vibration in either X, Y, Z Axis (ACGIH 2008)

\begin{tabular}{lcc}
\hline $\begin{array}{c}\text { Total Daily Exposure } \\
\text { Duration1* }\end{array}$ & $\begin{array}{c}\text { Values of the Dominant, Frequency-Weighted, rms, } \\
\text { Component Acceleration Which Shall not be Exceeded } \\
\text { m/* }\end{array}$ & $\mathrm{s}^{2}$ \\
\hline 4 hours and less than 8 & 4 & 0.40 \\
2 hours and less than 4 & 6 & 0.61 \\
1 hours and less than 2 & 8 & 0.81 \\
less than 1 hour & 12 & 1.22 \\
\hline
\end{tabular}

* The total time vibration enters the hand per day, whether continuously or intermittently.

** Typically, the accelerations of one axis show dominion to those of the other two axes.

$* * * \mathrm{~g}=9.81 \mathrm{~m} / \mathrm{s}^{2}$ 


\section{CHAPTER 4}

\section{MATHEMATICAL MODELS OF ASSEMBLY LINE DESIGN WITH THE LINEARIZED HAND ACTIVITY AND HAND-ARM VIBRATION CONSTRAINTS}

This chapter describes a mathematical model incorporating hand activity and hand-arm vibration into assembly line design. The objective of this model is to minimize the number of workers as well as control upper extremity exposures. The assumptions of the thesis, the linear representations of ergonomic measures and the optimization models are presented. Figure 4.1 and Figure 4.2 show the structures of hand activity and hand-arm vibration constraints.

\subsection{Assumptions}

The assumptions of the assembly line design models in this chapter are as follows.

- One worker charges only one workstation.

- Each task is assigned to only one station.

- The assembly line is a single model assembly line.

- Work time is longer than 4 hours per day. This is the precondition for calculating HAL.

- Rotating jobs are not considered.

- No different strength or ergonomic characteristic of individual workers is considered. 
- Workers conduct the assembly tasks based on the standard procedure so that each worker exerts the same force with the same work pace for the same task.

- Each worker exerts the same grip force in the same assembly task, so that vibration acceleration will not change because of the fluctuation of grip force.

- All tasks are already optimized in ergonomic postures, such as the angle of wrists and the distances between assembly workers and products.

These assumptions are necessary in order to create a general assembly line design model with the consideration of ergonomics. 


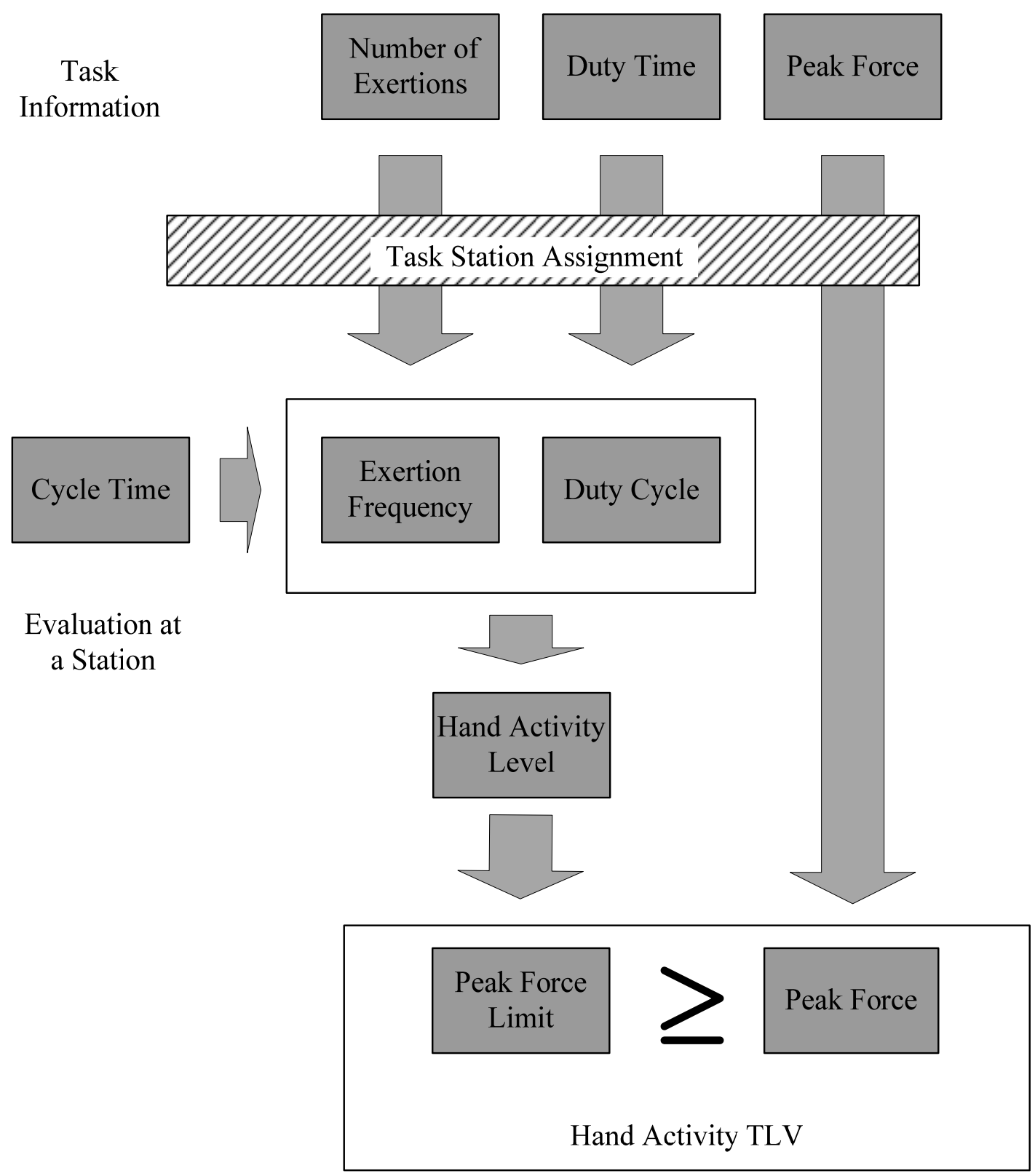

Figure 4.1 The relation between task assignment, task information, cycle time and hand activity TLV 


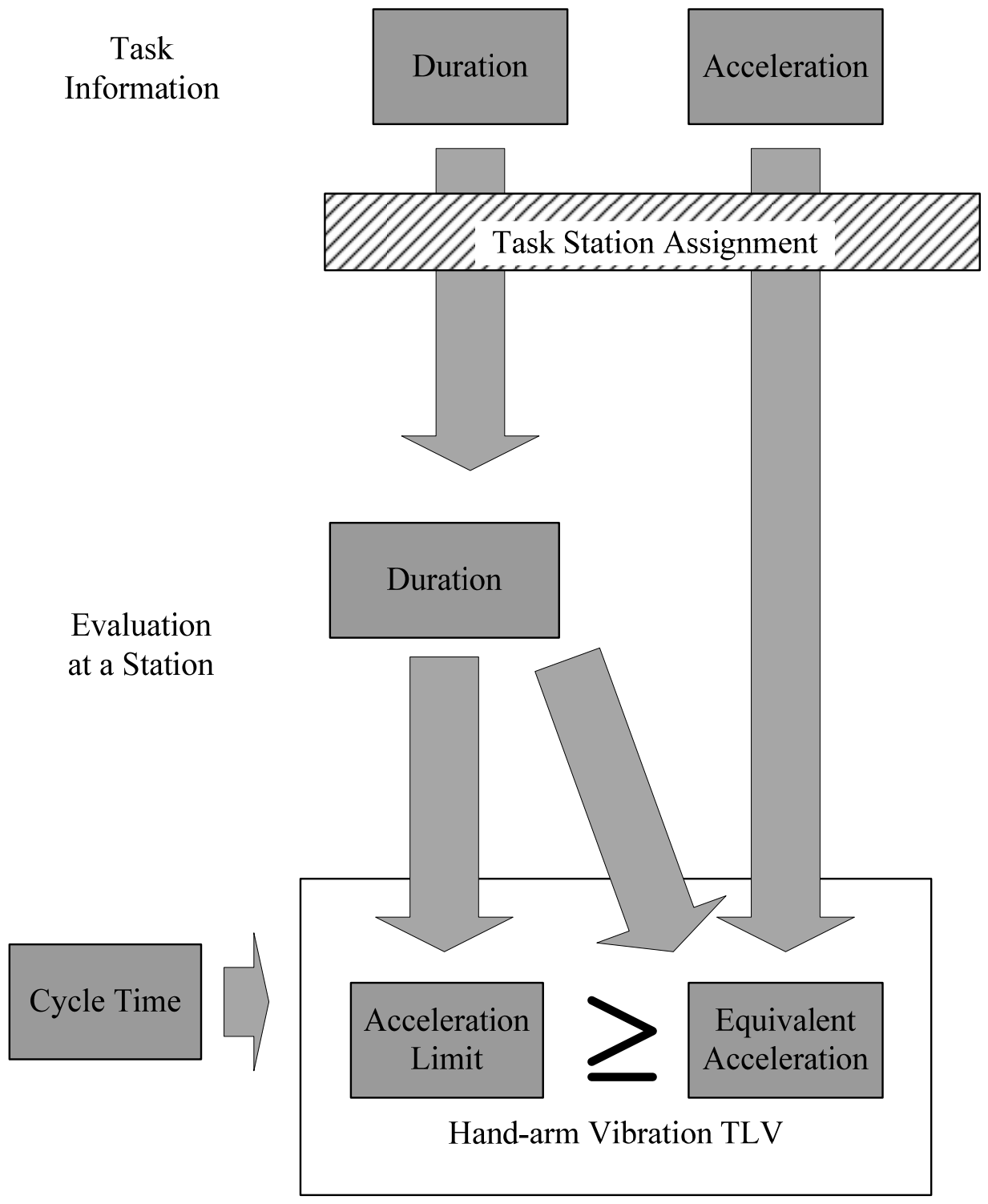

Figure 4.2 Structural diagram of relation between task assignment, task information, cycle time and hand-arm vibration TLV 


\subsection{Linear Formulas on Hand Activity and Hand-arm Vibration}

To build linearized relations between task assignment and HAL values, this research uses step functions and integer decision variables. The standard HAL evaluation procedure uses a look-up table, in which the row and column numbers are determined by exertion frequency and duty cycle values (ACGIH 2008). This look-up table procedure hinders the direct use of the HAL measure in linear assembly line design models. Therefore, this research develops functions that convert the table expression to linear equations.

This research uses two step-functions to use the exertion frequency and duty cycle tables. One step function relates the exertion frequency obtained from task assignment and the corresponding representative exertion frequency used in the look-up table (Eq. (7) and Table 4.1). This equation gives the row number $\left(r n_{s}^{h}\right)$ in Table 4.1. The other step function relates the duty cycle $\left(\mathrm{cn}_{\mathrm{s}}^{h}\right)$ attained from task assignment and the corresponding representative duty cycle used in the look-up table (Eq. (8) and Table 4.1). This equation gives the column number $\left(c n_{s}^{h}\right)$ in Table 4.1. These step functions can be easily converted to linear equations (Murty 1994), (Schoomer 1964, 773-777). Some optimization software even includes built-in features that convert these step functions automatically to linear equations (IBM ).

$$
\begin{aligned}
& r n_{s}^{h}=\sum_{p=1}^{R N} p \cdot \mathbf{1}\left(E F_{p}, e f_{s}^{h}\right) \\
& \text { where } \mathbf{1}\left(E F_{p}, e f_{s}^{h}\right)= \begin{cases}1 & \text { if } e f_{s}^{h} \in E F_{p} \\
0 & \text { if ef } f_{s}^{h} \notin E F_{p}\end{cases}
\end{aligned}
$$


$c n_{s}^{h}=\sum_{q=1}^{C N} q \cdot \mathbf{1}\left(D C_{q}, d c_{s}^{h}\right)$

where $\mathbf{1}\left(D C_{q}, d c_{s}^{h}\right)= \begin{cases}1 & \text { if } d c_{s}^{h} \in D C_{q} \\ 0 & \text { if } d c_{s}^{h} \notin D C_{q}\end{cases}$

Refer to Table 4.3 and Table 4.4 for the parameters in the equations.

The row and column numbers obtained by Eqs. (7)-(8) are used to select the corresponding HAL value. The linear equations below (Eqs. (9)-(10)) determine value of the HAL at each station using the row and column numbers from Eqs. (7) and (8) and the HAL value table (Table 4.1). A binary variable $y_{s, u}^{h}$ is defined to indicate the cell position in the HAL table. If the cell $u$ is selected for station $s$ then $y_{s, u}^{h}$ is one and zero otherwise. Then the following equations determine the value of $\mathrm{hal}_{\mathrm{s}}^{h}$.

$v_{s}^{h}=r n_{s}^{h}+R N \cdot\left(c n_{s}^{h}-1\right) \quad \forall s, \forall h$

$$
\begin{aligned}
& \sum_{u=1}^{R N \cdot C N} y_{s, u}^{h}=1 \quad \forall s, \forall u, \forall h \\
& v_{s}^{h}=\sum_{u=1}^{R N \cdot C N} u \cdot y_{s, u}^{h} \quad \forall s, \forall h \\
& h a l_{s}^{h}=\sum_{u=1}^{R N \cdot C N} H T_{u} \cdot y_{s, u}^{h} \quad \forall s, \forall h
\end{aligned}
$$

Eq. (9) determines the address in the HAL table (Table 4.1). Variable $v_{s}^{h}$ alone can represent the addresses of HALs. Equation (10) ensures only a single cell is selected from Table 4.1. Eq. (11) finds the only cell in Table 4.1 that should be used ( $u$ for which $y_{s, u}^{h}$ 
should be one). Eq. (12) assigns the corresponding HAL values using the $y_{s, u}^{h}$ value determined by Eq. (11). $H T_{u}$ represents the value of HAL when $v_{s}^{h}=u$ in Table 4.2. The linearization of the conventional look-up table based procedure is possible by converting the two-dimensional relations shown in Table 4.1 and development of new equations.

Table 4.1 Reference table of HAL with $m=5$ (ACGIH 2008)

\begin{tabular}{|c|c|c|c|c|c|c|}
\hline \multirow{2}{*}{$\begin{array}{l}\text { Frequency } \\
\text { (exertion/s) }\end{array}$} & \multirow{2}{*}{$\begin{array}{c}\text { Period } \\
\text { (s/exertion) }\end{array}$} & \multicolumn{5}{|c|}{ Duty Cycle (\%) } \\
\hline & & $0-20$ & $20-40$ & $40-60$ & $60-80$ & 80-100 \\
\hline 0.125 & 8.0 & $1\left(v_{11}=1\right)$ & $1\left(v_{12}=6\right)$ & $3\left(v_{13}=11\right)$ & $5\left(v_{14}=16\right)$ & $6\left(v_{15}=21\right)$ \\
\hline 0.25 & 4.0 & $2\left(v_{21}=2\right)$ & $2\left(v_{22}=7\right)$ & $3\left(v_{23}=12\right)$ & $5\left(v_{24}=17\right)$ & $6\left(v_{25}=22\right)$ \\
\hline 0.5 & 2.0 & $3\left(v_{31}=3\right)$ & $4\left(v_{32}=8\right)$ & $5\left(v_{33}=13\right)$ & $5\left(v_{34}=18\right)$ & $6\left(v_{35}=23\right)$ \\
\hline 1.0 & 1.0 & $4\left(v_{41}=4\right)$ & $5\left(v_{42}=9\right)$ & $5\left(v_{43}=14\right.$ & $6\left(v_{44}=19\right)$ & $7\left(v_{45}=24\right)$ \\
\hline 2.0 & 0.5 & $5\left(v_{51}=5\right)$ & $5\left(v_{52}=10\right)$ & $6\left(v_{53}=15\right)$ & $7\left(v_{54}=20\right)$ & $8\left(v_{55}=25\right)$ \\
\hline
\end{tabular}

ACGIH TLV is applied to set the limits of ergonomic measures in this research. The table considers the worst case for each unreachable entry of Table 2.2, so the results may be conservative. Such cases, however, will be rare. 
Table 4.2 The conversion of intermediate value $v_{s}^{h}$ to HAL

\begin{tabular}{|c|c|c|c|c|c|c|c|c|c|}
\hline$v_{s}^{h}$ & $h a l_{s}^{h}$ & $v_{s}^{h}$ & hal ${ }_{n_{s}^{h}}$ & $v_{s}^{h}$ & $h a l_{n_{s}^{h}}$ & $v_{s}^{h}$ & hal ${ }_{n_{s}^{h}}$ & $V_{s}^{h}$ & $h a l_{n}$ \\
\hline $1^{*}$ & 1 & 6 & 1 & 11 & 3 & 16 & 5 & 21 & 6 \\
\hline 2 & 2 & 7 & 2 & 12 & 3 & 17 & 5 & 22 & 6 \\
\hline 3 & 3 & 8 & 4 & 13 & 5 & 18 & 5 & 23 & 6 \\
\hline 4 & 4 & 9 & 5 & 14 & 5 & 19 & 6 & 24 & 7 \\
\hline 5 & 5 & 10 & 5 & 15 & 6 & 20 & 7 & 25 & 8 \\
\hline
\end{tabular}

Table 4.3 The set of ranges of exertion frequencies (ACGIH 2008)

\begin{tabular}{cc}
\hline$p$ (row index) & $E F_{p}$ (exertions/second) \\
\hline 1 & {$[0,0.125)$} \\
2 & {$[0.125,0.25)$} \\
3 & {$[0.25,0.5)$} \\
4 & {$[0.5,1)$} \\
5 & {$[1,2]$} \\
\hline
\end{tabular}

Table 4.4 The set of ranges of duty cycles (ACGIH 2008)

\begin{tabular}{cc}
\hline$q$ (column index) & $D C_{q}(\%)$ \\
\hline 1 & {$[0,0.2)$} \\
2 & {$[0.2,0.4)$} \\
3 & {$[0.4,0.6)$} \\
4 & {$[0.6,0.8)$} \\
5 & {$[0.8,1.0]$} \\
\hline
\end{tabular}


The acceleration limits are also shown in linear formulas. Eq. (6') is a linear form of Eq. (6) (ACGIH 2008), defining the equivalent frequency-weighted, rms, component acceleration. Eq. (13) shows the equivalent accelerations of workers $\left(a k_{e q, s}^{o}\right)$ should be always smaller than acceleration TLVs ( $\left.l a k_{e q, s}^{o}\right)$. Eq. (13') is obtained by multiplying $T D_{s}$ in both sides of Eq. (13). Eq. (14) is the expanded form of Eq. (6'). The left hand side of Eq. (14) is derived from Eq. (6'), and the right hand side is derived from Eq. (13').

$$
\begin{aligned}
& \left(a k_{e q, s}^{o}\right)^{2} \cdot T D_{s}=\sum_{i}^{I}\left(a k_{i}^{o}\right)^{2} \cdot x_{i s} \cdot v t_{i} \cdot N C \quad \forall s, \forall o \\
& a k_{e q, s}^{o} \leq l a k_{e q, s}^{o} \quad \forall s, \forall o \\
& \left(a k_{e q, s}^{o}\right)^{2} \cdot T D_{s} \leq\left(l a k_{e q, s}^{o}\right)^{2} \cdot T D_{s} \quad \forall s, \forall o \\
& \sum_{i}^{I}\left(a k_{i}^{o}\right)^{2} \cdot x_{i s} \cdot v t_{i} \cdot N C \leq\left(l a k_{e q, s}^{o}\right)^{2} \cdot T D_{s} \quad \forall s, \forall o
\end{aligned}
$$

Thus, the linear relations of task assignment and acceleration TLVs are established in Eq. (14).

Table 4.5 The conversion of daily vibration duration to acceleration TLV (ACGIH 2008)

$$
\begin{array}{ll}
l a k_{e q, s}^{o}\left(\mathrm{~m} / \mathrm{s}^{2}\right) & T D_{s} \text { (hour) } \\
\hline 4 & {[4,8]} \\
6 & {[2,4)} \\
8 & {[1,2)} \\
12 & {[0,1)} \\
\hline
\end{array}
$$

$8 \quad[1,2)$




\subsection{Optimization Model}

This section describes the optimization model for assembly line design. This model is to minimize the number of workstations while considering production rates, hand activity and hand-arm vibration. The main decision variable represents the task assignment to stations/workers. The models include two types of constraints: ergonomics and conventional assembly line design constraints. The ergonomic constraints include hand exertion frequency, duty cycle, normalized peak force (NPF), vibration acceleration and vibration duration. The conventional assembly line design constraints include cycle time and task precedence constraints.

The optimization model, including equations from Section 4.2, is presented as follows.

Min $z$

Subject to

$e f_{s}^{h}=\frac{\sum_{i=1}^{I} n e_{i}^{h} \times x_{i s}}{C T} \quad \forall s, \forall h$

$d c_{s}^{h}=\frac{\sum_{i=1}^{I} d t_{i}^{h} \cdot x_{i s}^{h}}{C T} \quad \forall s, \forall h$

$r n_{s}^{h}=\sum_{p=1}^{R N} p \cdot \mathbf{1}\left(E F_{p}, e f_{s}^{h}\right)$

$c n_{s}^{h}=\sum_{q=1}^{C N} q \cdot \mathbf{1}\left(D C_{q}, d c_{s}^{h}\right)$ 
$v_{s}^{h}=r n_{s}^{h}+R N \cdot\left(c n_{s}^{h}-1\right)$

$$
\sum_{u=1}^{R N \cdot C N} y_{s, u}^{h}=1 \quad \forall s, \forall u, \forall h
$$

$r n_{s}^{h}+R N \cdot\left(c n_{s}^{h}-1\right)=\sum_{u=1}^{R N \cdot C N} u \cdot y_{s, u}^{h} \quad \forall s, \forall h$

$h a l_{s}^{h}=\sum_{u=1}^{R N \cdot C N} H T_{u} \cdot y_{s, u}^{h} \quad \forall s, \forall h$

$n p f l_{s}^{h}=\frac{5}{9} h a l_{s}^{h}+5 \frac{5}{9} \quad \forall s, \forall h$

$n p f l_{s}^{h} \geq x_{i s} \cdot n p f_{s}^{h} \quad \forall s, \forall i, \forall h$

$T D_{s}=\sum_{i}^{I} v t_{i} \cdot x_{i s} \cdot N C \quad \forall s$

$\sum_{i}^{I}\left(a k_{i}^{o}\right)^{2} \cdot x_{i s} \cdot v t_{i} \cdot N C \leq\left(\operatorname{lak}_{e q_{T D_{s}}}^{o}\right)^{2} \cdot T D_{s} \quad \forall s, \forall o$

$Z=\sum_{s=1}^{S \max } s \cdot X_{I s}$

$\sum_{s=1}^{S \max } s \cdot x_{i s}=1 \quad \forall i$

$\sum_{i=1}^{I} t_{i} \cdot x_{i s} \leq C T \quad \forall s$ 
$\sum_{s=1}^{I} s \cdot x_{i s} \leq \sum_{s=1}^{I} s \cdot x_{j s} \quad i \in$ precedence of $j$

$x_{i s}, y_{s, u}^{h} \in\{1,0\} \quad \forall i, s, h, u$

The explanations of the models are as follows. The objective function, Eq. (15), is to minimize the number of workers (workstations). Constraint (1) indicates the exertion frequency is derived from dividing the total number of exertions by the cycle time (ACGIH 2008). Constraint (2) shows the duty cycle is linearly dependent on the duty time of each task. Constraints (7) can determine Table 4.1's row index based on exertion frequencies, and duty cycles can determine Table 4.1's column index by Constraints (8). Constraints (7)-(8) were explained in Section 4.2. Constraints (9)-(12) determine HAL values and were explained in Section 4.2. Constraint (3) represents AL (Bernard et al. 1994, 417-426). Constraint (4) shows NPF of a worker should be always less than AL. Constraint (5) represents the total daily vibration exposure duration of worker $s$. Constraint (14) ensures hand-arm vibration accelerations and was explained in Section 4.2 .

Constraints (17)-(20) are the traditional constraints in assembly line design. So called the "ghost task" is defined so that the task requires all the other tasks should be done before it. Thus, the ghost is always in the last station. All characteristics in the ghost task are zeros, so it will not affect the solutions of models. Constraint (17) ensures that the last station contains the ghost task for the precedence relation and the last station number is the total number of assembly line stations (workers). Constraint (18) shows every task can only be assigned to only one station once. Constraint (19) makes the sum of task times for each 
station under the cycle time. Constraint (20) makes sure the sequence of work stations does not conflict with task precedence (Scholl 1999).

This optimization function has the following characteristics. First, it is a mixed-integer linear program. Thus, (1) the linear form of the constraints allows faster calculation than other non-linear constraints found in the literature, (2) the ergonomic data tables used for the constraints can be conveniently replaced with more sophisticated tables or other ergonomic measure tables, and (3) other linear assembly line constraints can be incorporated in this optimization program easily. Second, the computational complexity of the optimization formulation is not significantly higher compared to general assembly line design formulation. 


\section{CHAPTER 5}

\section{NUMERICAL EXPERIMENTS AND DISCUSSION}

To verify if the models effectively control hand activity and vibration received by the upper-extremities in assembly line design, a numerical experiment is conducted. The solutions from traditional model and ergonomics considered model are compared.

\subsection{Manufacturing Task Description and Parameter Estimation}

A case study was conduct to design an assembly line for consumer electronics appliance (blender) assembly. The assembly process consists of 14 assembly tasks. The task descriptions and precedence are shown in Figure 5.1.

The hand activity data for these tasks are estimated from the assembly task analysis in IMSE 898 (Assembling Modeling) class project at University of Nebraska-Lincoln (Xu and Hao 2009) and vibration data are estimated based on a study by (Radwin and Armstrong 1985, 211-219). All tasks are assumed to be performed in standing posture. Data related to HAL and vibration are shown in Table 5.1. Normalized peak force (NPF) is obtained by the methodology introduced in Chapter 2 based on Table 5.2. The peak force applied in this case study is limited to grip force. These data were created by analyzing assembly tasks. The data from the student project is used as a sample set of data to initiate the model testing. The student attempted the tasks and then used their measured times and an estimate of the performance times as input data for the numerical experiments. The data, in this research, based on one subject, and multiple subject tests will be used in a future study to generate recommendations for practical use. 


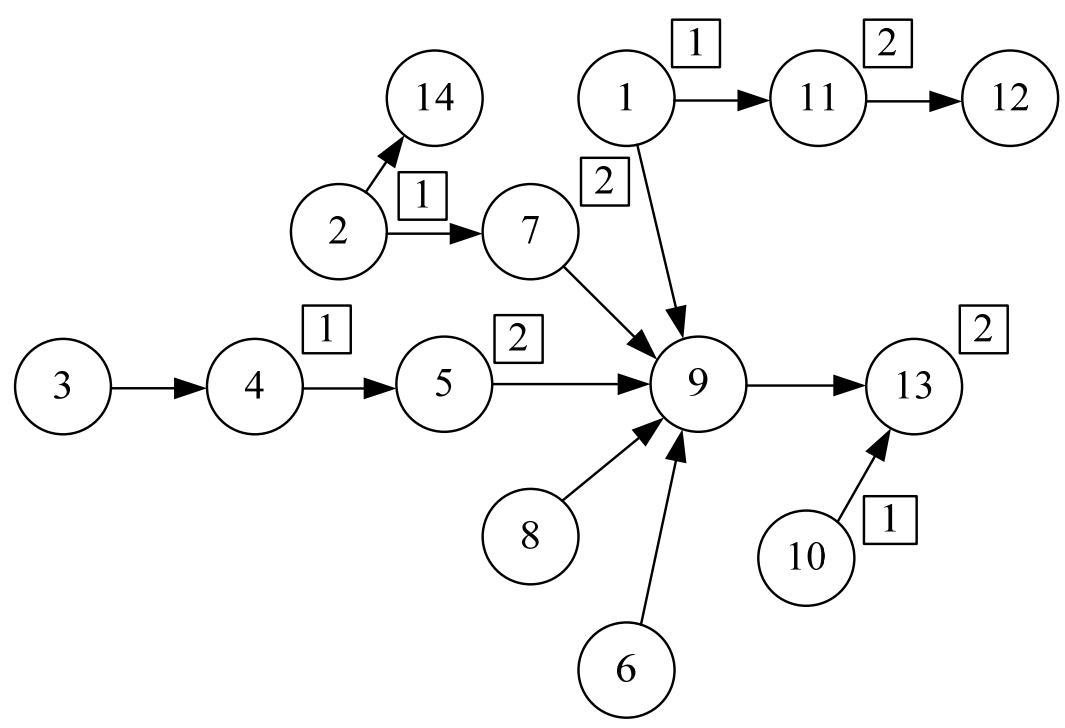

Task

Description

1 Placing Control Box on Body Roof by Automatic Shut-off Screwdriver

2 Placing Motor Base on Body Roof by Automatic Shut-off Screwdriver

$3 \quad$ Putting Magnet on Motor Base by bare Hands

$4 \quad$ Placing Motor Top on Motor Base by Automatic Shut-off Screwdriver

$5 \quad$ Fixing Motor Top on Motor Base by Clutch Screwdriver

$6 \quad$ Connecting Wires to Control Box by Plier

$7 \quad$ Fixing Moto Base to Body Roof by Clutch Screwdriver

8 Connecting Wires to Moto by Plier

$9 \quad$ Connecting Fan with Motor by Wrench

10 Connecting Body Bottom and Body Feet by Automatic Shut-off

Screwdriver

11 Fixing Control Box on Body Roof by Clutch Screwdriver

12 Pasting Label by Hands

13 Fixing Body Bottom by Clutch Screwdriver

14 Fixing Top Rod by Hands

The numbers in the circles represent assembly tasks. 1 and 2 represent vibration Profiles 1 and 2, respectively.

Figure 5.1 The task description and precedence of assembly tasks with vibration profiles 
Table 5.1 Data of exertion number, cycle time and NPF

\begin{tabular}{|c|c|c|c|c|c|c|c|c|c|c|c|c|c|c|}
\hline & & & & & & & & $\operatorname{ask~N}$ & & & & & & \\
\hline & 1 & 2 & 3 & 4 & 5 & 6 & 7 & 8 & 9 & 10 & 11 & 12 & 13 & 14 \\
\hline $\begin{array}{l}\text { Task Time } \\
\text { (Second) }\end{array}$ & 9.3 & 23.8 & 3.6 & 12.7 & 11.1 & 30.9 & 17.1 & 16.7 & 18.9 & 11.5 & 14.3 & 10.3 & 15.4 & 18.6 \\
\hline $\begin{array}{c}\text { Number of } \\
\text { Exertions }\left(\mathrm{R}^{*}\right)\end{array}$ & 3 & 6 & 2 & 3 & 3 & 3 & 5 & 4 & 6 & 2 & 3 & 3 & 3 & 6 \\
\hline $\begin{array}{l}\text { Number of } \\
\text { Exertions (L) }\end{array}$ & 1 & 2 & 2 & 1 & 3 & 3 & 5 & 4 & 1 & 2 & 3 & 3 & 3 & 6 \\
\hline $\begin{array}{l}\text { Duty Times } \\
\text { (R) (Second) }\end{array}$ & 5.8 & 7 & 2.2 & 8.3 & 6.7 & 3.3 & 11.4 & 9.1 & 4.0 & 7.4 & 10.3 & 1.8 & 5.5 & 5.7 \\
\hline $\begin{array}{l}\text { Duty Times } \\
\text { (L) (Second) }\end{array}$ & 1.8 & 1 & 2.2 & 8.3 & 7.0 & 4.8 & 10.0 & 7.1 & 0.6 & 7.0 & 8.8 & 1.8 & 5.0 & 8.0 \\
\hline $\begin{array}{l}\text { NPF of Task } \\
\text { (R) }\end{array}$ & 4.3 & 4.3 & 2.6 & 4.3 & 4.3 & 4.3 & 4.3 & 2.6 & 3.5 & 4.3 & 4.3 & 1.7 & 4.3 & 4.3 \\
\hline $\begin{array}{c}\text { NPF of Task } \\
\text { (L) }\end{array}$ & 2.8 & 2.8 & 2.8 & 2.8 & 2.8 & 1.9 & 2.8 & 2.8 & 2.8 & 2.8 & 1.9 & 1.9 & 2.8 & 2.8 \\
\hline $\begin{array}{l}\text { Vibration } \\
\text { Duration } \\
\text { (Second) }\end{array}$ & 5 & 4 & 0 & 3 & 2 & 0 & 4 & 0 & 0 & 7 & 2 & 0 & 3 & 0 \\
\hline $\begin{array}{l}\text { Acceleration } \\
\text { Profile }\end{array}$ & 1 & 1 & - & 1 & 2 & - & 2 & - & - & 1 & 2 & - & 2 & - \\
\hline
\end{tabular}

* “R” and "L" represent right and left hands, respectively. 
Table 5.2 Male power grip strengths in Newton (N) (Nemethi 1952, 65-66)

\begin{tabular}{cccc}
\hline Dominant (right) & Non-dominant (left) & Subject age & Population \\
\hline $463.5^{*}$ & 398.9 & $18-65$ & Office workers \\
532.1 & 474.3 & $18-65$ & Laborers \\
556.6 & 514.5 & $18-65$ & Skilled \\
589.0 & 532.1 & $18-65$ & Semi-skilled \\
\hline
\end{tabular}

Data with * mark represent the data used in this research.

The acceleration profiles were determined as follows. Because pneumatic tools cause considerable vibration in assembly line processes (Adamo, Martin and Johnson 2002, 134-140), this case study assumed the use of pneumatic tools. It is assumed that two types of pneumatic tools, Clutch Screwdriver and Automatic Shut-off Screwdriver, are used during assembling processes. Profile 1 represents a task placing screw using Automatic Shut-off Screwdriver. This task contains lower acceleration vibration but longer vibration duration compared to those of Profile 2. Profile 2 represents a task using Clutch Screwdriver tightening screws. The profiles of tasks are shown in Figure 5.1. This task causes relatively severe vibration acceleration and short vibration duration. The accelerations and the coordination of the two screwdrivers are shown Figure 5.2. The diameters of the two screwdrivers are assumed the same. All accelerations are frequencyweighted based on ISO 5349 and are explained in Appendix A. 


\section{Profile \#1}

Automatic Shut-off Screwdriver

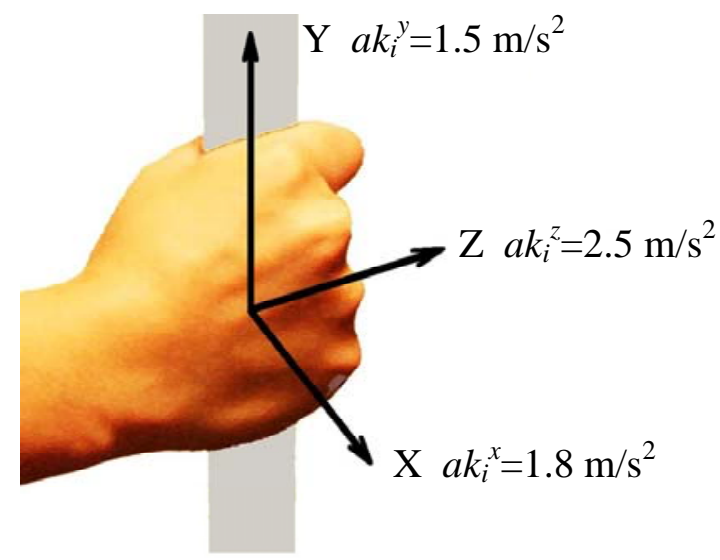

$\underline{\text { Profile \#2 }}$

Clutch Screwdriver

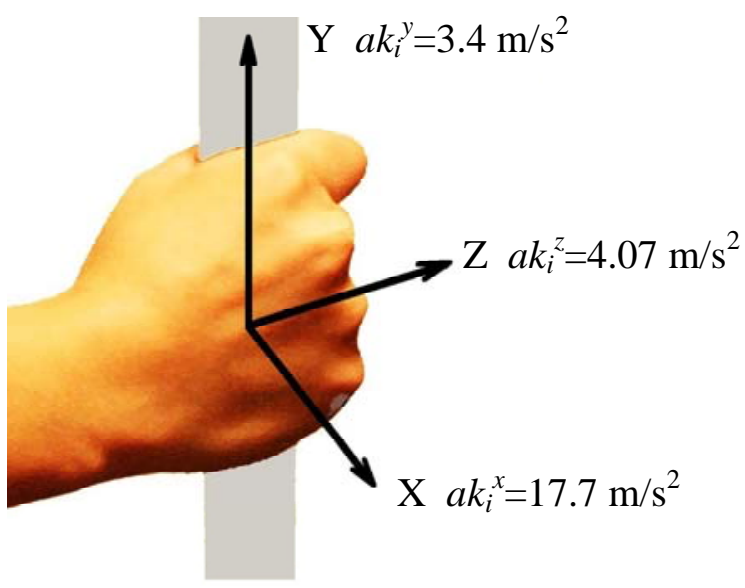

$a k_{i}^{o}=$ The frequency-weighted, rms acceleration of task $i$, direction $o=x, y, z$

Figure 5.2 The accelerations and the coordinate figures of the two screwdrivers. Adapted from (Radwin and Armstrong 1985, 211-219) 


\subsection{Results from Different Combinations of Ergonomic Constraints}

Four line design models (LBMC, LBMCH, LBMCV and LBMCHV) were compared. These models were different in terms of the different combination of hand activity and hand-arm vibration constraints included in the assembly line design formulations. The acronyms for the models are shown in Table 5.3. These assembly line design models were solved by a commercial MIP software package CPLEX® (IBM). The solution times took usually a few seconds, at most less than a minute, in a PC with $2.67 \mathrm{GHz}$ CPU.

Table 5.3 Acronyms for the line balancing models

\begin{tabular}{cl}
\hline Model & Combinations of Constraints \\
\hline LBMC & Conventional constraints only \\
LBMCH & Conventional and hand activity constraints \\
LBMCV & Conventional and vibration constraints \\
LBMCHV & Conventional, hand activity and vibration constraints \\
\hline
\end{tabular}

The result summarized is as a schematic diagram in Figure 5.3, and the detailed taskstation assignment is included in Table B.1in Appendix B. The exertion frequency, duty cycle, NPF and its TLV are shown in Appendix B. The vibration acceleration and duration is shown in Table B.5 in Appendix B. As shown in Figure 5.3, LBMCHV (the model with all hand activity and vibration constraints) is the only case in which all ergonomic exposures are below the TLVs. This is due to the added constraints in LBMCHV. 


\section{Flow of Material}

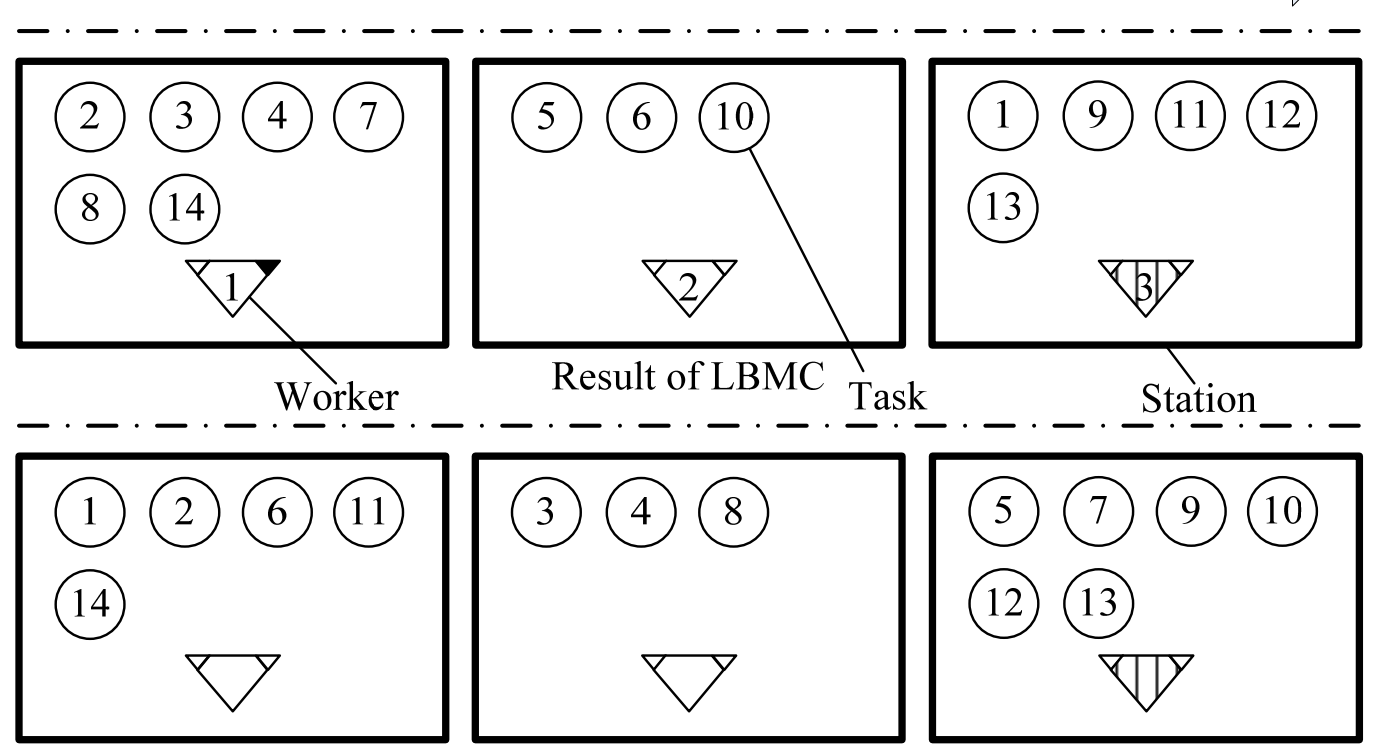

Result of LBMCH
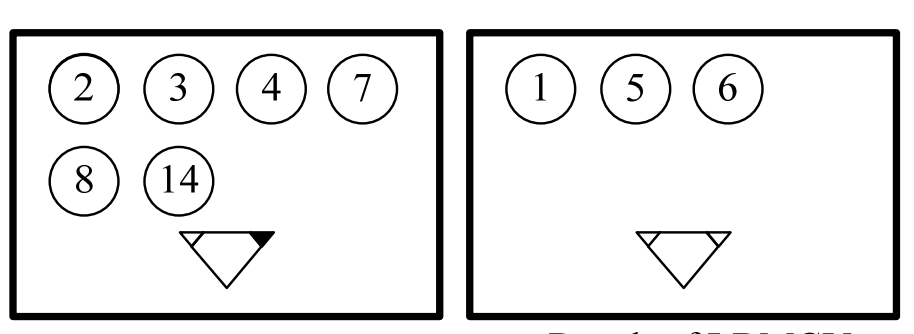

(9) 110

(13)

Result of LBMCV

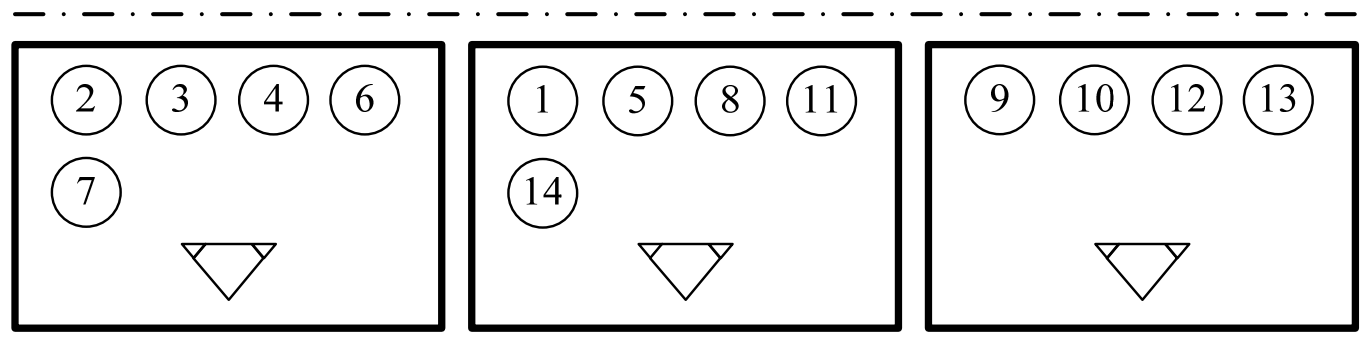

Result of LBMCHV

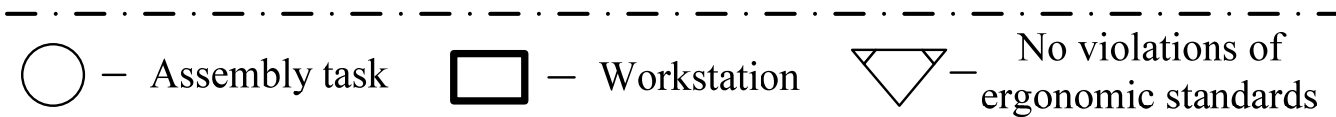
V - $\begin{gathered}\text { Worker' hand-arm } \\ \text { vibration exceeding }\end{gathered}$ vibration TLV

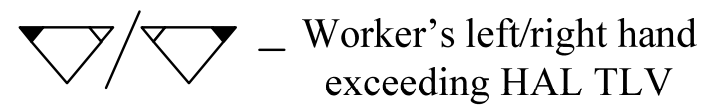

Figure 5.3 Results from different constraint combinations 
Figure 5.4 represents the HAL \& NPF values and TLVs. Table 5.4 shows the relative performance of each task. Table 5.5 shows dominant accelerations and TLV. The detailed analysis shows the violation of constraints in each case. For example, Figure 5.4 (a) and (c) show at least one of HAL values exceeded the AL line in the models not considering hand activity (LBMC, LBMCV). Figure 5.4 (b) shows that all HAL values satisfy the TLVs.

Table 5.4 shows the change of hand activity and vibration between LBMC and the LBMCHV. Table 5.4 shows considerable hand activity level change in LBMCH and LBMCHV, compared to LBMC: the stations with high HAL exposure in LBMC decreased HAL, whereas stations with relatively low exposure in LBMC increased HAL. HAL is more balanced in LBMCH and LBMCHV.

Figure 5.4 also shows the vibration accelerations did not satisfy TLV in the models without considering vibration (LBMC, LBMCH). Table 5.4 shows LBMCH did not improve the vibration condition. Station 3, which already exceeded vibration TLV in LBMC, even suffered higher vibration exposure than that in LBMC. However, the vibration accelerations were well controlled in LBMCV and LBMCHV.

These comparisons demonstrate that the lack of ergonomic considerations in line design may result in severe work conditions in terms of hand activity and vibration. This ergonomic problems in stations needs adjustment in working conditions in individual tasks or numerous trial-and-error based task switching between stations until all the ergonomic measures are satisfied. The new approach can help overcome this problem. 


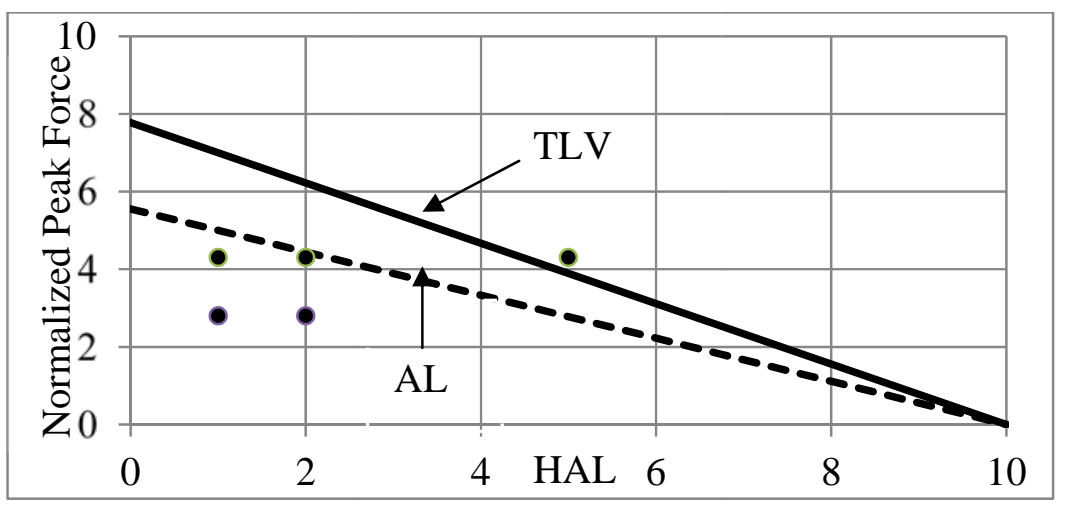

(a) HAL TLV of LBMC

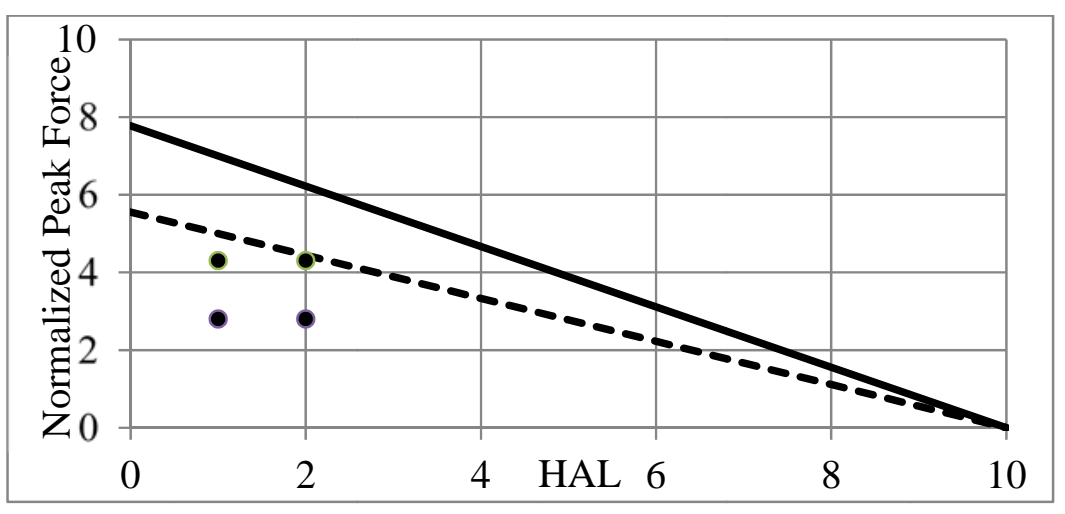

(b) HAL TLV of LBMCH

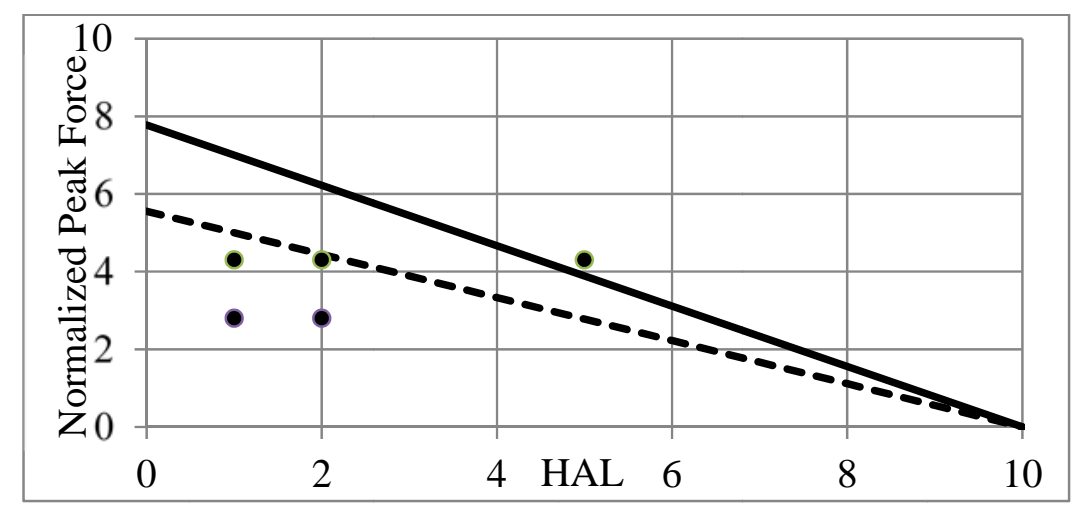

(c) HAL TLV of LBMCV 


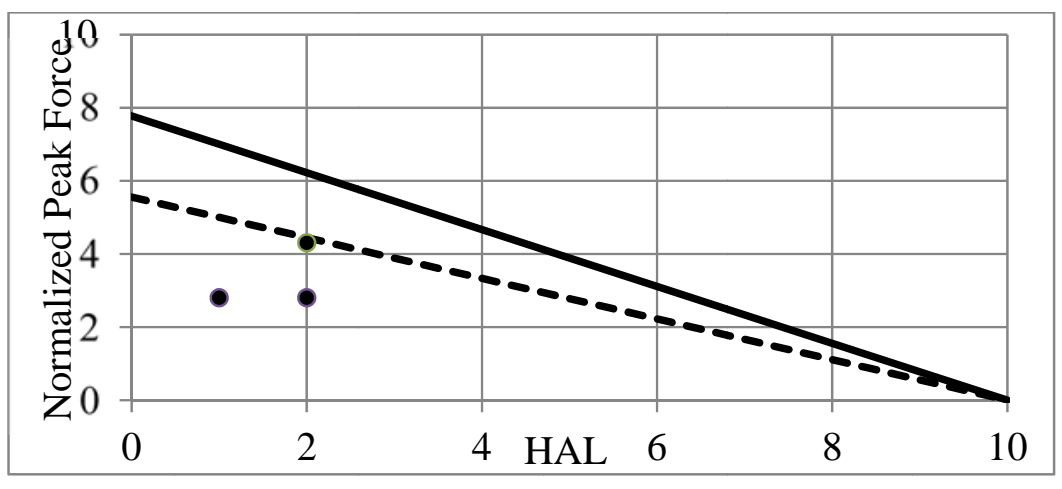

(d) HAL TLV of LBMCHV

Figure 5.4 HAL TLV of LBMC, LBMCH, LBMCV and LBMCHV. In each case, there are six points (each hand at three stations), but some points are indistinguishable because they have the same values in HAL and NPF

Table 5.4 Relative value of ergonomic measures compared to LBMC case

\begin{tabular}{|c|c|c|c|c|c|c|c|c|c|}
\hline & & ef (\%) & & $d c(\%)$ & & $n p f$ & $\%)$ & $a k(\%)$ & $d t(\%)$ \\
\hline & Hand & $\mathrm{R}$ & $\mathrm{L}$ & $\mathrm{R}$ & $\mathrm{L}$ & $\mathrm{R}$ & $\mathrm{L}$ & & \\
\hline LBMCH & $\begin{array}{l}\text { Station } \\
1 \\
2 \\
3\end{array}$ & $\begin{array}{r}-19.2 \\
12.5 \\
22.2\end{array}$ & $\begin{array}{r}-25.0 \\
-12.5 \\
54.6\end{array}$ & $\begin{array}{r}-26.5 \\
12.6 \\
34.3\end{array}$ & $\begin{array}{r}-33.3 \\
-6.4 \\
74.4\end{array}$ & $\begin{array}{l}0 \\
0 \\
0\end{array}$ & $\begin{array}{l}0 \\
0 \\
0\end{array}$ & $\begin{array}{r}-28.3 \\
-70.6 \\
6.0\end{array}$ & $\begin{array}{r}0 \\
-66.7 \\
60\end{array}$ \\
\hline LBMCV & $\begin{array}{l}1 \\
2 \\
3\end{array}$ & $\begin{array}{r}0 \\
12.5 \\
-5.6\end{array}$ & $\begin{array}{r}0 \\
-12.5 \\
9.1\end{array}$ & $\begin{array}{r}0 \\
-9.2 \\
5.8\end{array}$ & $\begin{array}{r}0 \\
-27.7 \\
28.9\end{array}$ & $\begin{array}{l}0 \\
0 \\
0\end{array}$ & $\begin{array}{l}0 \\
0 \\
0\end{array}$ & $\begin{array}{r}0 \\
12.8 \\
-8.5\end{array}$ & $\begin{array}{r}0 \\
-22.2 \\
20\end{array}$ \\
\hline LBMCHV & $\begin{array}{l}1 \\
2 \\
3\end{array}$ & $\begin{array}{l}-26.9 \\
137.5 \\
-22.2\end{array}$ & $\begin{array}{r}-35.0 \\
112.5 \\
-18.2\end{array}$ & $\begin{array}{l}-26.1 \\
116.1 \\
-31.8\end{array}$ & $\begin{array}{r}-28.1 \\
73.9 \\
-20.0\end{array}$ & $\begin{array}{l}0 \\
0 \\
0\end{array}$ & $\begin{array}{l}0 \\
0 \\
0\end{array}$ & $\begin{array}{r}0 \\
39.9 \\
-22.0\end{array}$ & $\begin{array}{l}0 \\
0 \\
0\end{array}$ \\
\hline
\end{tabular}

The relative values are calculated as $\frac{\mathrm{V}_{\text {variable }}^{\text {model }}-\mathrm{V}_{\text {variable }}^{\mathrm{LBMC}}}{\mathrm{V}_{\text {variable }}^{\mathrm{LBMC}}} \times 100 \%$, where variable represents ef, $d c, n p f$, $a k$ or $d t$, and model represents LBMCH, LBMCV or LBMCHV. 
Table 5.5 Vibration results

\begin{tabular}{ccccc}
\hline & $\begin{array}{c}\text { Worker } \\
\text { No. }\end{array}$ & $\begin{array}{c}\text { Equivalent, } \\
\text { Dominant, } \\
\text { Acceleration } \\
\left(\mathrm{m} / \mathrm{s}^{2}\right)\end{array}$ & $\begin{array}{c}\text { Daily } \\
\text { Vibration } \\
\text { Exposure } \\
\text { Duration } \\
\text { (hours) }\end{array}$ & $\begin{array}{c}\text { Acceleration } \\
\text { Limit }\left(\mathrm{m} / \mathrm{s}^{2}\right)\end{array}$ \\
\hline \multirow{2}{*}{ LBMC } & 1 & 10.8 & 0.88 & 12 \\
& 2 & 8.5 & 0.72 & 12 \\
& 3 & $12.6^{*}$ & 0.80 & 12 \\
LBMCH & 1 & 7.7 & 0.88 & 12 \\
& 2 & 2.5 & 0.24 & 12 \\
& 3 & $13.3^{*}$ & 1.28 & 8 \\
LBMCV & 1 & 10.8 & 0.88 & 12 \\
& 2 & 9.6 & 0.56 & 12 \\
& 3 & 11.5 & 0.96 & 12 \\
LBMCHV & 1 & 10.8 & 0.88 & 12 \\
& 2 & 11.9 & 0.72 & 12 \\
\hline
\end{tabular}

* The acceleration exceeds TLV. 


\section{CHAPTER 6}

\section{CONCLUSIONS AND RECOMMENDATIONS}

This research proposed a combined productivity and ergonomics methodology for assembly line design to help reduce the WMSDs in upper-body extremities among assembly workers, and successfully developed a model to verify the feasibility of the methodology. This research established linear formulas integrating ergonomic measures (exertion frequency, duty cycle, NPF, vibration acceleration and vibration duration) into task assignment models. Mixed integer programming (MIP) was applied to integrate ergonomic measures to the conventional assembly line characteristics (task precedence, cycle time and the number of work stations). Through numerical experiments, the research analyzed the effect of selected different ergonomic considerations by solving the MIP models with different combinations of ergonomic constraints. This analysis of the numerical experiments demonstrated the effectiveness of the new integrated approach compared to a conventional assembly line model without the ergonomic consideration. Thus, the numerical experiments demonstrated the feasibility of the modeling. This implies that this research successfully incorporates several ergonomic measurements into assembly design models, and the models may control the exposure of hands without sacrificing line efficiency. By the integration, this research help bridge the gap between ergonomics and assembly line design studies.

The new approach in this paper will help improve the practice by which we design an assembly line and reduce ergonomic risks. The linearized ergonomic constraint models allow more explicit integration of task assignment and ergonomic measures in line design. Thus, this approach helps to overcome the problem of the conventional assembly line 
design: separated assembly task assignment and ergonomic evaluations. In addition, the linearized ergonomic measures enable the use of efficient solution methods for linear assembly line design models. This methodology also opens the possibility of incorporating other diverse ergonomic characteristics of assembly tasks.

The research help reduce WMSD risks. The ergonomic measures related to hand exposures in all assembly workstations are controlled by the developed constraints. Other ergonomic measures and their exposure limits can be considered in similar ways in these models as well. Therefore, the research can be used to help prevent WMSDs among assembly workers by optimizing task assignment.

Future research will be conducted to broaden the scope of this research and increase the applicability in industrial settings. The main purpose of this research was to demonstrate the feasibility of the models integrating ergonomics and productivity measures. The results in this thesis, however, are limited for direct application in industrial settings, because the input performance times were estimated based upon non-experienced industry estimates (university students). The data were also based on experiments involving one subject, and tests with multiple subjects will be necessary to generate practical recommendations for industry. Studies of large-scale could address these issues in the future. 


\section{REFERENCES}

ACGIH. 2009. Hand activity level: $T L V^{\circledR}$ physical agents 7 th edition documentation.

ACGIH. 2008. 2008 TLVs and BEIs (ACGIH, TLVs and BEIs). American Conference of Governmental Industria.

ACGIH. ACGIH offers publications and products for occupational health professionals product detail a. Internet on-line. Available from <http://www.acgih.org/store/ProductDetail.cfm?id=652>. [7/13/2010, 2010].

ACGIH. TLV chemical substances introduction on the uses of TLVs and BEIs b. Internet on-line. Available from <http://www.acgih.org/products/tlvintro.htm>. [7/13/2010, 2010].

ACGIH. TLV physical agents introduction on the uses of TLVs and BEIs c. Internet online. Available from <https://www.acgih.org/Products/paintro.htm>. [7/13/2010, 2010].

Adamo, D. E., B. J. Martin, and P. W. Johnson. 2002. Vibration-induced muscle fatigue, a possible contribution to musculoskeletal injury. European Journal of Applied Physiology 88, no. 1: 134-140.

American National Standards Institute. ANSI S3.34-1986 guide for the measurement and evaluation of human exposure to vibration transmitted to the hand.Internet on-line. Available from <http://webstore.ansi.org/RecordDetail.aspx?sku=ANSI+S2.70-2006>. [8/27/2010, 2010].

Armstrong, T. J. 2008. Preventing waste due to fatigue and musculoskeletal disorders. MODAPTS News 25, no. 3: 3-4.

Baybars, I. 1986. A survey of exact algorithms for the simple assembly line balancing problem. Management Science : 909-932.

Becker, C., A. Scholl. 2006. A survey on problems and methods in generalized assembly line balancing. European Journal of Operational Research 168, no. 3: 694-715.

Bernard, B., S. Sauter, L. Fine, M. Petersen, and T. Hales. 1994. Job task and psychosocial risk factors for work-related musculoskeletal disorders among newspaper employees. Scandinavian Journal of Work, Environment \& Health 20, no. 6: 417-426.

Carayon, P., M. J. Smith, and M. C. Haims. 1999. Work organization, job stress, and work-related musculoskeletal disorders. Human Factors 41, no. 4: 644.

Carnahan, B. J., B. A. Norman, and M. S. Redfern. 2001. Incorporating physical demand criteria into assembly line balancing. IIE Transactions 33, no. 10: 875-887. 
Choi, G. 2009. A goal programming mixed-model line balancing for processing time and physical workload. Computers \& Industrial Engineering 57, no. 1: 395-400.

Drinkaus, P., R. Sesek, D. S. Bloswick, C. Mann, and T. Bernard. 2005. Job level risk assessment using task level ACGIH hand activity level TLV scores: a pilot study. International Journal of Occupational Safety and Ergonomics (JOSE) 11, no. 3: 263281.

Escorpizo, R., A. Moore. 2007. The effects of cycle time on the physical demands of a repetitive pick-and-place task. Applied Ergonomics 38, no. 5: 609-615.

Griffin, MJ. 1996. Handbook of human vibration. Academic Pr.

Health and Safety Executive. Musculoskeletal disorders Internet on-line. Available from <http://www.hse.gov.uk/msd/index.htm>. [7/13/2010, 2010].

Helander, M. 2006. A guide to human factors and ergonomics. Crc Press.

Hignett, S., L. McAtamney. 2000. Rapid entire body assessment (REBA). Applied Ergonomics 31, no. 2: 201-206.

IBM. IBM ILOG CPLEX optimization studio - software.Internet on-line. Available from $<$ http://www-01.ibm.com/software/integration/optimization/cplex-optimizationstudio/>. [7/13/2010, 2010].

International Organization for Standardization. ISO 5349 measurement and evaluation of human exposure to hand-transmitted vibration.Internet on-line. Available from

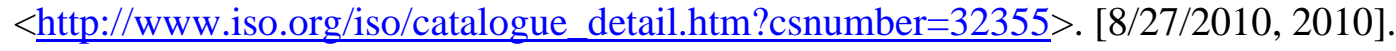

Kedlaya, D., J. Kim. Evaluation of the injured worker. 2007. Internet on-line. Available from < http://emedicine.medscape.com/article/314090-overview>. [2010, 9/23, 2010].

Latko, W. A., T. J. Armstrong, J. A. Foulke, G. D. Herrin, R. A. Rabourn, and S. S. Ulin. 1997. Development and evaluation of an observational method for assessing repetition in hand tasks. American Industrial Hygiene Association Journal 58, no. 4: 278-285.

McAtamney, L., E. Nigel Corlett. 1993. RULA: a survey method for the investigation of work-related upper limb disorders. Applied Ergonomics 24, no. 2: 91-99.

Moodie, C. L., H. H. Young. 1965. A heuristic method of assembly line balancing for assumptions of constant or variable work element times. Journal of Industrial Engineering 16: 23-29.

Murty, K. G. 1994. Operations research: Deterministic optimization models. PrenticeHall, Inc. Upper Saddle River, NJ, USA. 
Nemethi, C. E. 1952. An evaluation of hand grip in industry. Industrial Medicine \& Surgery 21, no. 2 (Feb) : 65-66.

Occhipinti, E. 1998. OCRA: a concise index for the assessment of exposure to repetitive movements of the upper limbs. Ergonomics 41, no. 9: 1290-1311.

Ontario Ministry of Labour. Prevent workplace pains \& strains! it's time to take action! | ontario ministry of labour Internet on-line. Available from <http://www.labour.gov.on.ca/english/hs/pubs/ergonomics/is_ergonomics.php>. [7/27/2010, 2010].

Peter Vi, Hon B. S. Musculoskeletal disorders February 28, 2007 2007. Internet on-line. Available from <http://www.csao.org/uploadfiles/magazine/vol11no3/musculo.htm>. [7/13/2010, 2010].

Punnett, L., D. H. Wegman. 2004. Work-related musculoskeletal disorders: the epidemiologic evidence and the debate. Journal of Electromyography and Kinesiology 14, no. 1: 13-23.

Pyykko, I., M. Farkkila, J. Toivanen, O. Korhonen, and T. Hyvarinen. 1976.

Transmission of vibration in the hand-arm system with special reference to changes in compression force and acceleration. Scandinavian Journal of Work, Environment and Health 2: 87-95.

Radwin, R. G., T. J. Armstrong. 1985. Assessment of hand vibration exposure on an assembly line. American Industrial Hygiene Association Journal 46, no. 4: 211-219.

Rekiek, B., and A. Delchambre. 2006. Assembly line design: The balancing of mixedmodel hybrid assembly lines with genetic algorithms. Springer-Verlag New York Inc.

Salveson, M. E. 1955. The assembly line balancing problem. Journal of Industrial Engineering 6, no. 3: 18-25.

Scholl, A. 1999. Balancing and sequencing of assembly lines. Publications of Darmstadt Technical University, Institute for Business Studies (BWL) .

Scholl, A., C. Becker. 2006. State-of-the-art exact and heuristic solution procedures for simple assembly line balancing. European Journal of Operational Research 168, no. 3 : 666-693.

Schoomer, B. A. 1964. The incorporation of step functions and ramp functions into a linear programming model. Operations Research 12, no. 5: 773-777.

Seth, V., R. Lee Weston, and A. Freivalds. 1999. Development of a cumulative trauma disorder risk assessment model for the upper extremities. International Journal of Industrial Ergonomics 23, no. 4: 281-291. 
Smith, M. J., P. C. Sainfort. 1989. A balance theory of job design for stress reduction. International Journal of Industrial Ergonomics 4, no. 1: 67-79.

Spallek, M., W. Kuhn, S. Uibel, A. van Mark, and D. Quarcoo. 2010. Work-related musculoskeletal disorders in the automotive industry due to repetitive work implications for rehabilitation. Journal of occupational medicine and toxicology (London, England) 5 (Apr 7) : 6.

White, W. W. 1961. Comments on a paper by Bowman. Operations Research 9, no. 2: 274-276.

Xu, Z., G. Hao. 2009. IMSE 898 Term Project: Assembly of Oster 6640 Blender. 


\section{APPENDIX A}

THE PROCEDURES FOR CALCULATING FREQUENCY WEIGHTED

\section{ACCELERATION}

The frequency weighted acceleration is calculated by $a k_{w}=\sqrt{\sum_{f}^{F}\left(K_{f} \cdot a_{f}\right)^{2}}$ and Figure A.2 and Figure A.1, where $K_{f}=$ the $f$-th one-third-octave band (weighting factors in

Table A.1), $a_{f}=$ the measured acceleration in the $f$-th one-third-octave band (Figure A.2 and Figure A.1), and $F=$ the number of one-third-octave bands (International Organization for Standardization ).

Table A.1 Frequency-weighting factors for hand-arm vibration (International Organization for Standardization)

\begin{tabular}{|l|l|l|l|}
\hline $\begin{array}{l}\text { Central } \\
\text { frequency } \\
(\mathrm{Hz})\end{array}$ & $\begin{array}{l}\text { Weighting } \\
\text { factor }\left(K_{f}\right)\end{array}$ & $\begin{array}{l}\text { Central } \\
\text { frequency } \\
(\mathrm{Hz})\end{array}$ & $\begin{array}{l}\text { Weighting } \\
\text { factor }\left(K_{f}\right)\end{array}$ \\
\hline 6.3 & 1.0 & 100 & 0.16 \\
\hline 8 & 1.0 & 125 & 0.125 \\
\hline 10 & 1.0 & 160 & 0.1 \\
\hline 12.5 & 1.0 & 200 & 0.08 \\
\hline 16 & 1.0 & 250 & 0.063 \\
\hline 20 & 0.8 & 315 & 0.05 \\
\hline 25 & 0.63 & 400 & 0.04 \\
\hline 31.5 & 0.5 & 500 & 0.03 \\
\hline 40 & 0.4 & 630 & 0.025 \\
\hline 50 & 0.3 & 800 & 0.02 \\
\hline 63 & 0.25 & 1000 & 0.016 \\
\hline 80 & 0.2 & 1250 & 0.0125 \\
\hline
\end{tabular}


$\mathrm{X}$-axis

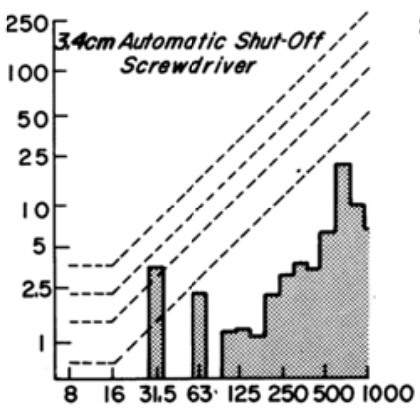

Y-axis

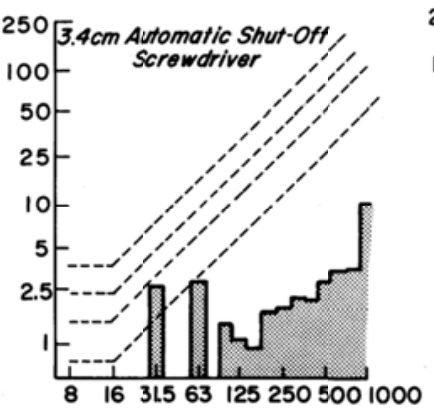

Z-axis

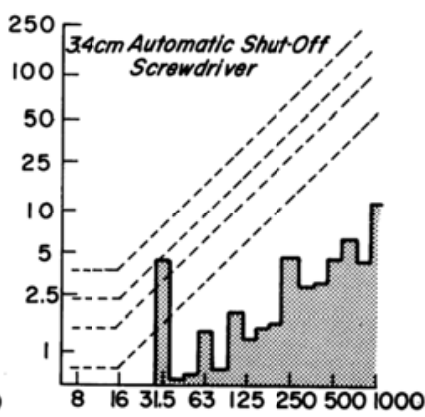

Figure A.1 One-third octave band spectra for the $3.4 \mathrm{~cm}$ diameter automatic shut-off screwdriver (Radwin and Armstrong 1985, 211-219)

$\mathrm{X}$-axis

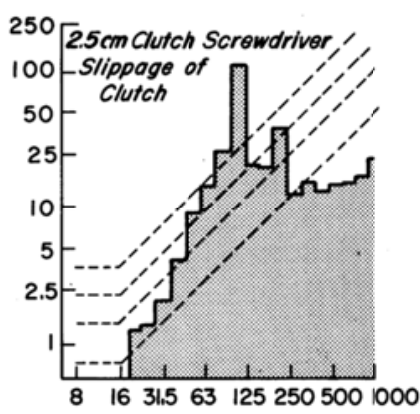

Y-axis

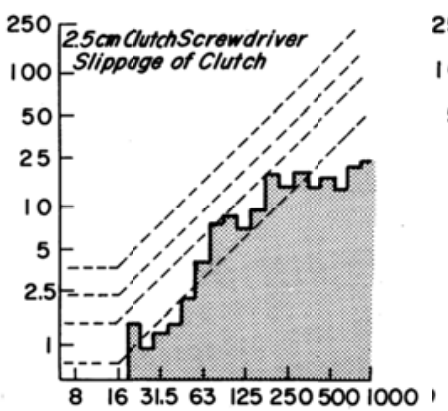

Z-axis

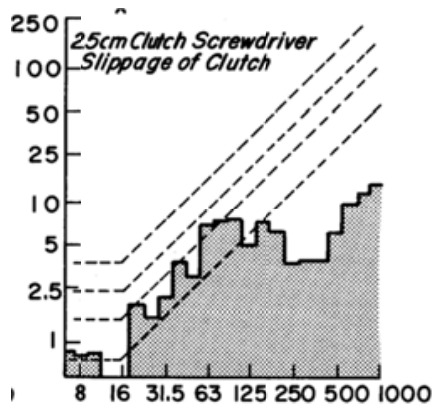

Figure A.2 One-third octave band spectra for the $2.5 \mathrm{~cm}$ diameter clutch screwdriver in the slippage of the clutch condition (Radwin and Armstrong 1985, 211-219) 
APPENDIX B

RESULTS OF LBMC, LBMCH, LBMCV AND LBMCHV

Table B.1 Hand activity result of LBMC

\begin{tabular}{|c|c|c|c|}
\hline Station & Station 1 & Station 2 & Station 3 \\
\hline Tasks Assigned & $\begin{array}{l}\text { F2, F3, F4, F7, } \\
\text { F8, F14 }\end{array}$ & F5, F6, F10 & $\begin{array}{c}\text { F1, F9, F11, } \\
\text { F12, F13 }\end{array}$ \\
\hline Exertion Frequency (R) & 0.26 & 0.08 & 0.18 \\
\hline Exertion Frequency (L) & 0.20 & 0.08 & 0.11 \\
\hline Duty Cycle (R) & 0.437 & 0.174 & 0.274 \\
\hline Duty Cycle (L) & 0.368 & 0.188 & 0.18 \\
\hline HAL (R) & 5 & 1 & 2 \\
\hline HAL (L) & 2 & 1 & 1 \\
\hline NPF (R) & 4.3 & 4.3 & 4.3 \\
\hline NPF (L) & 2.8 & 2.8 & 2.8 \\
\hline NPF TLV (R) & 2.7778 & 5 & 4.4444 \\
\hline NPF TLV (L) & 4.4444 & 5 & 5 \\
\hline
\end{tabular}


Table B.2 Hand activity result of LBMCH

\begin{tabular}{|c|c|c|c|}
\hline Station & Station 1 & Station 2 & Station 3 \\
\hline Tasks Assigned & $\begin{array}{c}\text { F1, F2, F6, F11, } \\
\text { F14 }\end{array}$ & F3, F4, F8 & $\begin{array}{c}\text { F5, F7, F9, } \\
\text { F10, F12, F13 }\end{array}$ \\
\hline Exertion Frequency (R) & 0.21 & 0.09 & 0.22 \\
\hline Exertion Frequency (L) & 0.15 & 0.07 & 0.17 \\
\hline Duty Cycle (R) & 0.321 & 0.196 & 0.368 \\
\hline Duty Cycle (L) & 0.244 & 0.176 & 0.314 \\
\hline HAL (R) & 2 & 1 & 2 \\
\hline HAL (L) & 2 & 1 & 2 \\
\hline NPF (R) & 4.3 & 4.3 & 4.3 \\
\hline NPF (L) & 2.8 & 2.8 & 2.8 \\
\hline NPF TLV (R) & 4.4444 & 5 & 4.4444 \\
\hline NPF TLV (L) & 4.4444 & 5 & 4.4444 \\
\hline
\end{tabular}


Table B.3 Hand activity result of LBMCV

\begin{tabular}{|c|c|c|c|}
\hline Station & Station 1 & Station 2 & Station 3 \\
\hline Tasks Assigned & $\begin{array}{c}\text { F2, F3, F4, F7, } \\
\text { F8, F14 }\end{array}$ & F1, F5, F6 & $\begin{array}{c}\text { F9, F10, F11, } \\
\text { F12, F13 }\end{array}$ \\
\hline Exertion Frequency (R) & 0.26 & 0.09 & 0.17 \\
\hline Exertion Frequency (L) & 0.20 & 0.07 & 0.12 \\
\hline Duty Cycle (R) & 0.437 & 0.158 & 0.29 \\
\hline Duty Cycle (L) & 0.366 & 0.136 & 0.232 \\
\hline HAL (R) & 5 & 1 & 2 \\
\hline HAL (L) & 2 & 1 & 1 \\
\hline NPF (R) & 4.3 & 4.3 & 4.3 \\
\hline NPF (L) & 2.8 & 2.8 & 2.8 \\
\hline NPF TLV (R) & 2.7778 & 5 & 4.4444 \\
\hline NPF TLV (L) & 4.4444 & 5 & 5 \\
\hline
\end{tabular}


Table B.4 Hand activity result of LBMCHV

\begin{tabular}{|c|c|c|c|}
\hline Station & Station 1 & Station 2 & Station 3 \\
\hline Tasks Assigned & F2, F3, F4, F6, F7 & $\begin{array}{c}\mathrm{F} 1, \mathrm{~F} 5, \mathrm{~F} 8, \mathrm{~F} 11, \\
\mathrm{~F} 14\end{array}$ & $\begin{array}{c}\text { F9, F10, F12, } \\
\text { F13 }\end{array}$ \\
\hline Exertion Frequency (R) & 0.19 & 0.19 & 0.14 \\
\hline Exertion Frequency (L) & 0.13 & 0.17 & 0.09 \\
\hline Duty Cycle (R) & 0.323 & 0.376 & 0.187 \\
\hline Duty Cycle (L) & 0.263 & 0.327 & 0.144 \\
\hline HAL (R) & 2 & 2 & 2 \\
\hline HAL (L) & 2 & 2 & 1 \\
\hline NPF (R) & 4.3 & 4.3 & 4.3 \\
\hline NPF (L) & 2.8 & 2.8 & 2.8 \\
\hline TLV of NPF (R) & 4.4444 & 4.4444 & 4.4444 \\
\hline TLV of NPF (L) & 4.4444 & 4.4444 & 5 \\
\hline
\end{tabular}


Table B.5 Detailed vibration results

\begin{tabular}{|c|c|c|c|c|c|c|}
\hline \multirow{2}{*}{ Model } & \multirow{2}{*}{$\mathrm{S}$} & \multicolumn{3}{|c|}{$\begin{array}{c}\text { Equivalent, Frequency-Weighted } \\
\text { Component Acceleration in }\end{array}$} & \multirow{2}{*}{$\begin{array}{c}\text { Daily } \\
\text { Vibration } \\
\text { Exposure } \\
\text { Duration }\end{array}$} & \multirow{2}{*}{$\begin{array}{l}\text { Acceleratior } \\
\text { Limit }\left(\mathrm{m} / \mathrm{s}^{2}\right)\end{array}$} \\
\hline & & $\begin{array}{l}X \text {-axis } \\
\left(\mathrm{m} / \mathrm{s}^{2}\right)\end{array}$ & $\begin{array}{l}\text { Y-axis } \\
\left(\mathrm{m} / \mathrm{s}^{2}\right)\end{array}$ & $\begin{array}{l}\text { Z-axis } \\
\left(\mathrm{m} / \mathrm{s}^{2}\right)\end{array}$ & & \\
\hline \multirow{3}{*}{ LBMC } & 1 & $10.8^{*}$ & 2.4 & 3.1 & 0.88 & 12 \\
\hline & 2 & 8.5 & 2.1 & 2.9 & 0.72 & 12 \\
\hline & 3 & 12.6 & 2.6 & 3.4 & 0.80 & 12 \\
\hline \multirow{3}{*}{ LBMCH } & 1 & 7.8 & 2.0 & 2.9 & 0.88 & 12 \\
\hline & 2 & 1.8 & 1.5 & 2.5 & 0.24 & 12 \\
\hline & 3 & 13.3 & 2.7 & 3.5 & 1.28 & 8 \\
\hline \multirow{3}{*}{ LBMCV } & 1 & 10.8 & 2.3 & 3.2 & 0.88 & 12 \\
\hline & 2 & 9.6 & 2.2 & 3.0 & 0.56 & 12 \\
\hline & 3 & 11.5 & 2.5 & 3.3 & 0.96 & 12 \\
\hline \multirow{3}{*}{ LBMCHV } & 1 & 10.8 & 2.4 & 3.2 & 0.88 & 12 \\
\hline & 2 & 11.9 & 2.5 & 3.3 & 0.72 & 12 \\
\hline & 3 & 9.8 & 2.3 & 3.1 & 0.80 & 12 \\
\hline
\end{tabular}

* Shaded cells represent the values in them are dominant accelerations 


\title{
APPENDIX C \\ THE COMPUTER PROGRAM OF THE OPTIMIZATION
}

Two computer codes were used to solve the problems in this study. Both codes are for a commercial MIP software package CPLEX ${ }^{\circledR}$ (IBM) Version 11.2.0. The first code, named Code-1, is for the direct implementation of the mathematical model in Section 4.3. The second one, named Code-2, is a modified code to reduce the computation time by using an efficient built-in function in CPLEX for representing piecewise linear functions. The model and data files for the both codes are shown below in the following order:

\author{
C1. Code-1 Model \\ C2. Code-1 Data \\ C3. Code-2 Model \\ C4. Code-2 Data
}




\section{C1. Code-1 Model}

int $\mathrm{N}=\ldots$;

range station=1..N;

\{string $\}$ task $=\ldots$;

float tasktime $[$ task $]=\ldots$;

int $\mathrm{c}=\ldots$;

int taskpreced[task][task] =...;

$\{$ string $\}$ cell $=\ldots$;

int cellvalue1[cell]=...;

int HT1[cell]=...;

int cellvalue2[cell]=...;

int HT2[cell]=...;

//Ei1

int exertion1[task $]=\ldots$;

//tfi1

float forcetime1 $[$ task $]=\ldots$;

//vforce1 
float vforce1[task]=...;

//Ei2

int exertion2 $[$ task $]=\ldots$;

//tfi2

float forcetime2[task]=...;

//vforce2

float vforce2 $[$ task $]=\ldots$;

//akxi

float accelerationx $[\operatorname{task}]=\ldots$;

//akyi

float accelerationy[task] $=.$. ;

//akzi

float accelerationz[task]=...;

//tai

float vibrationtime[task $]=\ldots$;

//variable

dvar boolean x[task][station]; 
dvar boolean y1[cell][station];

dvar boolean y2[cell][station];

dvar int+ m;

dvar float+ tempx1[station];

dvar float+ tempy1[station];

dvar float+ tempa1[station];

dvar float+ tempb1[station];

dvar float+ tempc1[station];

dvar float+ tempx2[station];

dvar float+ tempy2[station];

dvar float+ tempa2[station];

dvar float+ tempb2[station];

dvar float+ tempc2[station];

dvar float+ HAL1[station];

dvar float+ Peakforcelimit1[station];

dvar float+ HAL2[station];

dvar float+ Peakforcelimit2[station]; 
dvar float+ peakforce1[station];

dvar float+ peakforce2[station];

dvar float+ jobtime[station];

dvar float+ taskduration1[station];

dvar float+ taskduration2[station];

dvar float+ exertionnumber1[station];

dvar float+ exertionnumber2[station];

dvar float+ tempxd[station];

dvar float+ tempxe[station];

dvar float+ tempxN1[station];

dvar float+ tempxN2[station];

dvar float+ vibrationlimitx[station];

dvar float+ tempyd[station];

dvar float+ tempye[station];

dvar float+ tempyN1[station];

dvar float+ tempyN2[station];

dvar float+ vibrationlimity[station]; 
dvar float+ tempzd[station];

dvar float+ tempze[station];

dvar float+ tempzN1[station];

dvar float+ tempzN2[station];

dvar float+ vibrationlimitz[station];

//Objective

minimize m;

//Constraints

subject to \{

ct01:

forall ( $\mathrm{k}$ in station)

tempx1[k]==sum(i in task)(x[i][k]*exertion $1[\mathrm{i}] / \mathrm{c})$;

ct02:

forall ( $\mathrm{k}$ in station)

tempy $1[\mathrm{k}]==\operatorname{sum}(\mathrm{i}$ in task $)(\mathrm{x}[\mathrm{i}][\mathrm{k}] *$ forcetime $1[\mathrm{i}] / \mathrm{c})$; 
ct03:

forall ( $\mathrm{k}$ in station)

tempa1[k]==piecewise $\{0$-> 0.12499; 1 -> 0.12499; 0 -> 0.2499; 1 -> 0.2499; 0 -> 0.4999; 1 -> 0.4999;0 -> 0.9999; 1 -> 0.9999;0\}(0,1)tempx1[k];

ct04:

forall ( $\mathrm{k}$ in station)

tempb1[k]==piecewise $\{0$-> 0.1999; 1 -> 0.1999; 0 -> 0.3999; 1 -> 0.3999; 0 -> 0.5999; 1 -> 0.5999;0 -> 0.7999; 1 -> 0.7999;0\}(0,1)tempy1[k];

ct101:

forall ( $\mathrm{k}$ in station)

$\operatorname{sum}(\mathrm{u}$ in cell $)(\mathrm{y} 1[\mathrm{u}][\mathrm{k}])==1$;

ct102:

forall ( $\mathrm{k}$ in station)

tempa1[k]+5*(tempb1[k]-1)==sum(u in cell)(cellvalue1[u]*y1[u][k]);

ct103:

forall ( $\mathrm{k}$ in station)

$\operatorname{HAL} 1[\mathrm{k}]==\operatorname{sum}(\mathrm{u}$ in cell $)\left(\mathrm{HT} 1[\mathrm{u}]^{*} \mathrm{y} 1[\mathrm{u}][\mathrm{k}]\right)$; 
ct07:

forall ( $\mathrm{k}$ in station)

Peakforcelimit1 $[\mathrm{k}]==-(5 / 9) *$ HAL1 $[\mathrm{k}]+5+(5 / 9)$;

ct13:

forall ( $\mathrm{k}$ in station)

Peakforcelimit1[k]>=max(i in task)(x[i][k]*vforce1[i]);

ct200:

forall ( $\mathrm{k}$ in station)

peakforce1 $[\mathrm{k}]==\max (\mathrm{i}$ in task $)(\mathrm{x}[\mathrm{i}][\mathrm{k}] *$ vforce1[i]);

ct31:

forall ( $\mathrm{k}$ in station)

tempx2[k]==sum(i in task)(x[i][k]*exertion2[i]/c);

ct32:

forall ( $\mathrm{k}$ in station)

tempy $2[\mathrm{k}]==\operatorname{sum}(\mathrm{i}$ in task $)(\mathrm{x}[\mathrm{i}][\mathrm{k}] *$ forcetime $2[\mathrm{i}] / \mathrm{c})$;

ct33:

forall ( $\mathrm{k}$ in station) 
tempa2[k]==piecewise $\{0$-> 0.12499; 1 -> 0.12499; 0 -> 0.2499; 1 -> 0.2499; 0 -> 0.4999; 1 -> 0.4999;0 -> 0.9999; 1 -> 0.9999;0\}(0,1)tempx2[k];

ct34:

forall ( $\mathrm{k}$ in station)

tempb2[k]==piecewise $\{0$-> 0.1999; 1 -> 0.1999; 0 -> 0.3999; 1 -> 0.3999; 0 -> 0.5999; 1 -> 0.5999;0 -> 0.7999; 1 -> 0.7999;0\}(0,1)tempy2[k];

ct201:

forall ( $\mathrm{k}$ in station)

$\operatorname{sum}(\mathrm{u}$ in cell $)(\mathrm{y} 2[\mathrm{u}][\mathrm{k}])==1$;

ct202:

forall ( $\mathrm{k}$ in station)

tempa2[k]+5*(tempb2[k]-1)==sum(u in cell)(cellvalue2[u]*y2[u][k]);

ct203:

forall ( $\mathrm{k}$ in station)

HAL2 $[\mathrm{k}]==\operatorname{sum}(\mathrm{u}$ in cell $)\left(\mathrm{HT} 2[\mathrm{u}]^{*} \mathrm{y} 2[\mathrm{u}][\mathrm{k}]\right)$;

ct37:

forall ( $\mathrm{k}$ in station) 
Peakforcelimit2[k]==-(5/9)*HAL2[k]+5+(5/9);

ct43:

forall ( $\mathrm{k}$ in station)

Peakforcelimit2[k]>=max(i in task)(x[i][k]*vforce2[i]);

ct213:

forall ( $\mathrm{k}$ in station)

peakforce2[k]==max(i in task $)\left(x[\mathrm{i}][\mathrm{k}]^{*}\right.$ vforce2[i]);

ct14:

$\mathrm{m}==\operatorname{sum}\left(\mathrm{k}\right.$ in station) $\mathrm{k}^{*} \mathrm{x}[\mathrm{f} 15 "][\mathrm{k}]$

ct15:

forall (i in task)

$\operatorname{sum}(\mathrm{k}$ in station $) \mathrm{x}[\mathrm{i}][\mathrm{k}]==1$;

ct16:

forall ( $\mathrm{k}$ in station)

sum(i in task)tasktime $[\mathrm{i}]^{*} \mathrm{x}[\mathrm{i}][\mathrm{k}]<=\mathrm{C}$;

ct17:

forall (i ,j in task:taskpreced[i][j]>0) 
$\operatorname{sum}\left(e\right.$ in station) $e^{*} x[i][e]<=\operatorname{sum}(f$ in station $) f^{*} x[j][f]$;

ct1001:

forall ( $\mathrm{k}$ in station)

jobtime $[\mathrm{k}]==\operatorname{sum}(\mathrm{i}$ in task)(x[i][k]*tasktime[i]);

ct1002:

forall ( $\mathrm{k}$ in station)

exertionnumber1[k]==sum(i in task)(x[i][k]*exertion1[i]);

ct1003:

forall ( $\mathrm{k}$ in station)

exertionnumber2[k]==sum(i in task)(x[i][k]*exertion2[i]);

ct1004:

forall ( $\mathrm{k}$ in station)

taskduration $1[\mathrm{k}]==\operatorname{sum}(\mathrm{i}$ in task $)(\mathrm{x}[\mathrm{i}][\mathrm{k}] *$ forcetime1[i]);

ct1005:

forall ( $\mathrm{k}$ in station)

taskduration $2[\mathrm{k}]==\operatorname{sum}(\mathrm{i}$ in task $)(\mathrm{x}[\mathrm{i}][\mathrm{k}] *$ forcetime2[i]);

ct5: 
forall ( $\mathrm{k}$ in station)

sum(i in task)accelerationx[i]*vibrationtime[i] ${ }^{* x[i][k] * 8 * 3600 / c==t e m p x d[k] * 3600 ; ~}$

ct6:

forall ( $\mathrm{k}$ in station)

$\operatorname{sum}(\mathrm{i}$ in task $)(8 *$ vibrationtime $[\mathrm{i}] * x[\mathrm{i}][\mathrm{k}] / \mathrm{c})==$ tempxe[k];

ct7:

forall ( $\mathrm{k}$ in station)

tempxN1[k]==piecewise $\{144$-> 1;64 -> 2;36 -> 4;16\}tempxe[k];

ct8:

forall ( $\mathrm{k}$ in station)

tempxN2[k]==piecewise $\{0$-> 1;80 -> 1;0 -> 2;56 -> 2;0 -> 4;80 -> 4;0\} tempxe[k];

ct9:

forall ( $\mathrm{k}$ in station)

vibrationlimitx $[\mathrm{k}]==$ tempxN1[k]-tempxN2[k];

ct910:

forall ( $\mathrm{k}$ in station)

tempxd[k]<=vibrationlimitx $[\mathrm{k}]$; 
ct911:

forall ( $\mathrm{k}$ in station)

sum(i in task)accelerationy[i]*vibrationtime $[\mathrm{i}] * \mathrm{x}[\mathrm{i}][\mathrm{k}] * 8 / \mathrm{c}==$ tempyd $[\mathrm{k}]$;

ct912:

forall ( $\mathrm{k}$ in station)

$\operatorname{sum}(\mathrm{i}$ in task $)\left(8^{*}\right.$ vibrationtime $\left.[\mathrm{i}] * \mathrm{x}[\mathrm{i}][\mathrm{k}] / \mathrm{c}\right)==$ tempye $[\mathrm{k}]$;

ct913:

forall ( $\mathrm{k}$ in station)

tempyN1[k]==piecewise $\{144$-> 1;64 -> 2;36 -> 4;16\}tempye[k];

ct914:

forall ( $\mathrm{k}$ in station)

tempyN2[k]==piecewise $\{0$-> 1;80 -> 1;0 -> 2;56 -> 2;0 -> 4;80 -> 4;0\}tempye[k];

ct915:

forall ( $\mathrm{k}$ in station)

vibrationlimity[k]==tempyN1[k]-tempyN2[k];

ct916:

forall ( $\mathrm{k}$ in station) 
tempyd $[\mathrm{k}]<=$ vibrationlimity $[\mathrm{k}]$;

ct917:

forall ( $\mathrm{k}$ in station)

sum(i in task)accelerationz[i]*vibrationtime[i]*x[i][k]*8/c==tempzd[k];

ct918:

forall ( $\mathrm{k}$ in station)

sum(i in task) $\left(8^{*}\right.$ vibrationtime[i]*x[i][k]/c)==tempze[k];

ct19:

forall ( $\mathrm{k}$ in station)

tempzN1[k]==piecewise $\{144$-> 1;64 -> 2;36 -> 4;16\}tempze[k];

ct20:

forall ( $\mathrm{k}$ in station)

tempzN2[k]==piecewise $\{0$-> 1;80 -> 1;0 -> 2;56 -> 2;0 -> 4;80 -> 4;0\}tempze[k];

ct21:

forall ( $\mathrm{k}$ in station)

vibrationlimitz $[\mathrm{k}]==$ tempzN1[k]-tempzN2[k];

ct22: 
C15

forall ( $\mathrm{k}$ in station)

tempzd $[\mathrm{k}]<=$ vibrationlimitz $[\mathrm{k}]$;

\} 


\section{C2. Code-1 Data}

$\mathrm{N}=5$;

task = "f1", "f2", "f3", "f4","f5", "f6", "f7", "f8", "f9", "f10", "f11","f12","f13","f14","f15"\};

\begin{tabular}{|c|c|c|c|c|c|}
\hline tasktime= & {$[9.3$,} & 23.8, & 3.6, & 12.7, & 11.1, \\
\hline & 30.9 & 17.1, & 16.7, & 18.9, & 11.5, \\
\hline & 14.3, & 10.3, & 15.4, & 18.6, & J \\
\hline
\end{tabular}

cell = "c1", "c2", "c3", "c4","c5", "c6", "c7", "c8", "c9", "c10", "c11","c12","c13","c14","c15","c16","c17","c18","c19","c20","c21","c22","c23","c24","c 25"\};

cellvalue1 $=\quad[1,2,3,4,5,6,7,8,9,10,11,12,13,14,15,16,17,18,19,20,21,22,23,24,25] ;$

cellvalue2 $=\quad[1,2,3,4,5,6,7,8,9,10,11,12,13,14,15,16,17,18,19,20,21,22,23,24,25] ;$

$c=100$;

$\mathrm{HT} 1=\quad[1,2,3,4,5,1,2,4,5,5,3,3,5,5,6,5,5,5,6,7,6,6,6,7,8]$;

$\mathrm{HT} 2=\quad[1,2,3,4,5,1,2,4,5,5,3,3,5,5,6,5,5,5,6,7,6,6,6,7,8] ;$

taskpreced $=$

//F1 F2 F3 F4 F5 F6 F7 F8 F9 F10 F11 F12 F13 F14 F15 
[[0

$\begin{array}{lllll}, 0 & , 0 & , 0 & , 0 & , 0 \\ , 0 & , 0 & , 1 & , 0 & , 1 \\ , 1 & , 1 & , 0 & , 1], & / / F 1\end{array}$

[0

, 0

,0

, 0

, 0

, 0

,1

,1

, 0

, 0

, 0

,1

,1],

//F2

[0

, 0

,1

,1

, 0

, 0

,1

, 0

,0

, 0

, 0

,1],

//F3

[0

, 0

, 0

,0

,1

, 0

,0

, 0

,1

, 0

,0

, 0

,1

,1],

//F4

[0

, 0

,0

, 0

, 0

, 0

, 0

, 0

,1

, 0

, 0

,0

,1

,1],

//F5

[0

,0

,0

, 0

, 0

, 0

, 0

, 0

,1

, 0

, 0

,0

,1

,1],

//F6

[0

$\begin{array}{lll}, 0 & , 0 & , 0 \\ , 0 & , 0 & , 1 \\ , 0 & , 1 & , 0\end{array}$

, 0

$\begin{array}{ll}, 0 & , 0\end{array}$

,1

, 0

, 0

, 0

,1],

//F7 
[0

$\begin{array}{lllll}, 0 & , 0 & , 0 & , 0 & , 0 \\ , 0 & , 0 & , 1 & , 0 & , 0 \\ , 0 & , 1 & , 0 & , 1], & \text { //F8 }\end{array}$

[0

,0

,0

,0

,0

,0

,0

,0

,0

,0

,0

,1

,1],

//F9

[0

,0

,0

,0

,0

,0

,0

,0

,0

, 0

,0

,0

,1

,1],

//F10

[0

,0

,0

,0

,0

, 0

,0

,0

,0

,0

,0

,1

,0

,1],

//F11

[0

,0

,0

,0

,0

,0

,0

,0

,0

,0

,0

,0

,0

,1],

//F12

[0

,0

,0

,0

,0

,0

,0

,0

,0

,0

,0

,0

,0

,1],

//F13

[0

, 0
, 0
, 0

,0

,0

,0

,0

,0

,0

,0

,0

,0

,0

,1],

//F14 


\begin{tabular}{|c|c|c|c|c|c|}
\hline$[0$ & 0 & , 0 & 0 & , 0 & 0 \\
\hline & ,0 & , 0 & 0 & 0 & 0 \\
\hline & 0 & , 0 & 0 & ,0]]; & $/ / F 15$ \\
\hline$/ / \mathrm{f} \mathrm{f}$ & 1", "f2" & 4","f5" & f7", "f & 'f10", & \\
\hline "f11","f12"," & f13","f1 & & & & \\
\hline exertion1= & {$[3$,} & 6 & 2 & 3 & 3 \\
\hline & 3 & 5 & 4 & 6 & 2 \\
\hline & 3 & 3 & 3 & 6 & 0]; \\
\hline forcetime1= & {$[5.8$,} & 7 & 2.2 & 8.3, & 6.7 \\
\hline & 3.3 & 11.4, & 9.1, & 4, & 7.4 \\
\hline & 10.3, & 1.8, & 5.5, & 5.7 & 0]; \\
\hline vforce1= & {$[4.3$} & 4.3, & 2.6 & 4.3 & 4.3, \\
\hline & 4.3 & 4.3, & 2.6, & 3.5 , & 4.3, \\
\hline & 4.3, & 1.7, & 4.3, & 4.3, & 0]; \\
\hline exertion2= & {$[1$,} & 2 & 2 & 1 , & 3 \\
\hline & 3 & 5 & 4 & 1 , & 2 \\
\hline & 3 & 3 & 3 & 6 & 0]; \\
\hline forcetime2= & {$[1.8$,} & 1, & 2.2, & 8.3, & 7 \\
\hline & 4.8 & 10 & 7.1 , & 0.6 & 7 \\
\hline & 8.8, & 1.8, & 5 & 8 & 0]; \\
\hline
\end{tabular}




\begin{tabular}{|c|c|c|c|c|}
\hline \multirow[t]{2}{*}{ vforce2= } & {$[2.8$,} & 2.8 & 2.8 & 2.8, \\
\hline & 1.9, & 2.8 & 2.8, & 2.8 \\
\hline & 1.9, & 1.9, & 2.8, & 2.8, \\
\hline
\end{tabular}

acceleration $x=[3.24,3.24,0,3.24,313.29,0,313.29, \quad 0, \quad 0,3.24,313.29$, $0,313.29, \quad 0,0]$;

accelerationy $=[2.25,2.25, \quad 0,2.25,11.56, \quad 0, \quad 11.56, \quad 0, \quad 0, \quad 2.25, \quad 11.56$, $0, \quad 11.56,0,0]$

accelerationz $=[6.25,6.25,0,6.25,16.5649,0, \quad 16.5649,0,0,6.25$, $16.5649, \quad 0, \quad 16.5649, \quad 0, \quad 0]$

vibrationtime $=[5$,

4 ,

0

3 ,

2,

0 ,

4 ,

0

0

7,

2,

0 ,

3,

0 ,

0]; 


\section{C3. Code-2 Model}

int $\mathrm{N}=\ldots$;

range station=1..N;

\{string $\}$ task $=\ldots$;

float tasktime[task $]=\ldots$;

int $\mathrm{c}=\ldots$;

int taskpreced[task][task]=...;

//Ei1

int exertion $1[$ task $]=\ldots$;

//tfi1

float forcetime1 $[$ task $]=\ldots$;

//vforce1

float vforce1[task]=...;

//Ei2

int exertion2 $[$ task $]=\ldots$;

//tfi2

float forcetime2[task]=...; 
//vforce2

float vforce2 $[$ task $]=\ldots$;

//akxi

float accelerationx[task] $=\ldots$;

//akyi

float accelerationy[task] $=\ldots$;

//akzi

float accelerationz $[\operatorname{task}]=\ldots$;

//tai

float vibrationtime[task] $=\ldots$;

//variable

dvar boolean x[task][station];

dvar int+ m;

dvar float+ tempx1[station];

dvar float+ tempy1[station];

dvar float+ tempa1[station];

dvar float+ tempb1[station]; 
dvar float+ tempc1[station];

dvar float+ tempx2[station];

dvar float+ tempy2[station];

dvar float+ tempa2[station];

dvar float+ tempb2[station];

dvar float+ tempc2[station];

dvar float+ HAL1[station];

dvar float+ Peakforcelimit1[station];

dvar float+ HAL2[station];

dvar float+ Peakforcelimit2[station];

dvar float+ peakforce1[station];

dvar float+ peakforce2[station];

dvar float+ jobtime[station];

dvar float+ taskduration1[station];

dvar float+ taskduration2[station];

dvar float+ exertionnumber1[station];

dvar float+ exertionnumber2[station]; 
dvar float+ tempxd[station];

dvar float+ tempxe[station];

dvar float+ tempxN1[station];

dvar float+ tempxN2[station];

dvar float+ vibrationlimitx[station];

dvar float+ tempyd[station];

dvar float+ tempye[station];

dvar float+ tempyN1[station];

dvar float+ tempyN2[station];

dvar float+ vibrationlimity[station];

dvar float+ tempzd[station];

dvar float+ tempze[station];

dvar float+ tempzN1[station];

dvar float+ tempzN2[station];

dvar float+ vibrationlimitz[station];

//Objective

minimize m; 
subject to \{

ct01:

forall ( $\mathrm{k}$ in station)

tempx1[k]==sum(i in task)(x[i][k]*exertion1[i]/c);

ct02:

forall ( $\mathrm{k}$ in station)

tempy $1[\mathrm{k}]==\operatorname{sum}(\mathrm{i}$ in task $)(\mathrm{x}[\mathrm{i}][\mathrm{k}] *$ forcetime $1[\mathrm{i}] / \mathrm{c})$;

ct03:

forall ( $\mathrm{k}$ in station)

tempa1[k]==piecewise $\{0$-> 0.12499; 1 -> 0.12499; 0 -> 0.2499; 1 -> 0.2499; 0 -> 0.4999; 1 -> 0.4999;0 -> 0.9999; 1 -> 0.9999;0\}(0,1)tempx1[k];

ct04:

forall ( $\mathrm{k}$ in station)

tempb1[k]==piecewise $\{0$-> 0.1999; 1 -> 0.1999; 0 -> 0.3999; 1 -> 0.3999; 0 -> 0.5999; 1 -> 0.5999;0 -> 0.7999; 1 -> 0.7999;0\}(0,1)tempy1[k];

ct05:

forall ( $\mathrm{k}$ in station) 
tempc1[k]==tempa1[k]+5*(tempb1[k]-1);

ct06:

forall ( $\mathrm{k}$ in station)

HAL1[k]==piecewise $\{0->1 ; 1->5 ;-4->6 ; 1->7 ; 2->8 ; 1->9 ; 0->10 ;-2->11 ; 0->12 ; 2->13 ; 0-$

>14;1->15;-1->16;0->18;1->20;-1->21;0->23;1->25;0\}(0,1)tempc1[k]

ct07:

forall ( $\mathrm{k}$ in station)

Peakforcelimit1[k]==-(5/9)*HAL1[k]+5+(5/9);

ct13:

forall ( $\mathrm{k}$ in station)

Peakforcelimit1[k]>=max(i in task)(x[i][k]*vforce1[i]);

ct200:

forall ( $\mathrm{k}$ in station)

peakforce1[k]==max(i in task)(x[i][k]*vforce1[i]);

ct31:

forall ( $\mathrm{k}$ in station)

tempx2[k]==sum(i in task $)(x[\mathrm{i}][\mathrm{k}] *$ exertion2 $[\mathrm{i}] / \mathrm{c})$; 
ct32:

forall ( $\mathrm{k}$ in station)

tempy $2[\mathrm{k}]==\operatorname{sum}(\mathrm{i}$ in task $)(\mathrm{x}[\mathrm{i}][\mathrm{k}] *$ forcetime $2[\mathrm{i}] / \mathrm{c})$;

ct33:

forall ( $\mathrm{k}$ in station)

tempa2[k]==piecewise $\{0->0.12499 ; 1$-> 0.12499; 0 -> 0.2499; 1 -> 0.2499; 0 -> 0.4999; 1 -> 0.4999;0 -> 0.9999; 1 -> 0.9999;0\}(0,1)tempx2[k];

ct34:

forall ( $\mathrm{k}$ in station)

tempb2[k]==piecewise $\{0$-> 0.1999; 1 -> 0.1999; 0 -> 0.3999; 1 -> 0.3999; 0 -> 0.5999; 1 -> 0.5999;0 -> 0.7999; 1 -> 0.7999;0\}(0,1)tempy2[k];

ct35:

forall ( $\mathrm{k}$ in station)

tempc $2[\mathrm{k}]==$ tempa $2[\mathrm{k}]+5 *($ tempb2 $[\mathrm{k}]-1)$;

ct36:

forall ( $\mathrm{k}$ in station) 
HAL2[k]==piecewise $\{0->1 ; 1->5 ;-4->6 ; 1->7 ; 2->8 ; 1->9 ; 0->10 ;-2->11 ; 0->12 ; 2->13 ; 0-$ >14;1->15;-1->16;0->18;1->20;-1->21;0->23;1->25;0\}(0,1)tempc2[k];

ct37:

forall ( $\mathrm{k}$ in station)

Peakforcelimit2[k]==-(5/9)*HAL2[k]+5+(5/9);

ct43:

forall ( $\mathrm{k}$ in station)

Peakforcelimit2[k]>=max(i in task)(x[i][k]*vforce2[i]);

ct202:

forall ( $\mathrm{k}$ in station)

peakforce2 $[\mathrm{k}]==\max (\mathrm{i}$ in task $)(\mathrm{x}[\mathrm{i}][\mathrm{k}] *$ vforce2[i]);

ct14:

$\mathrm{m}==\operatorname{sum}\left(\mathrm{k}\right.$ in station) $\mathrm{k}^{*} \mathrm{x}[\mathrm{f} 15 "][\mathrm{k}]$;

ct15:

forall (i in task)

$\operatorname{sum}(\mathrm{k}$ in station $) \mathrm{x}[\mathrm{i}][\mathrm{k}]==1$;

ct16: 
forall ( $\mathrm{k}$ in station)

$\operatorname{sum}(\mathrm{i}$ in task)tasktime[i]*x[i][k]<=c;

ct17:

forall (i , in task:taskpreced[i][j] $>0$ )

$\operatorname{sum}\left(e\right.$ in station) $e^{*} x[\mathrm{i}][\mathrm{e}]<=\operatorname{sum}(\mathrm{f}$ in station $) \mathrm{f}^{*} \mathrm{x}[\mathrm{j}][\mathrm{f}]$;

ct1001:

forall ( $\mathrm{k}$ in station)

jobtime $[\mathrm{k}]==\operatorname{sum}(\mathrm{i}$ in task $)\left(\mathrm{x}[\mathrm{i}][\mathrm{k}]{ }^{*}\right.$ tasktime[i]);

ct1002:

forall ( $\mathrm{k}$ in station)

exertionnumber1[k]==sum(i in task)(x[i][k]*exertion1[i]);

ct1003:

forall ( $\mathrm{k}$ in station)

exertionnumber2[k]==sum(i in task)(x[i][k]*exertion2[i]);

ct1004:

forall ( $\mathrm{k}$ in station)

taskduration1 $[\mathrm{k}]==\operatorname{sum}(\mathrm{i}$ in task $)(\mathrm{x}[\mathrm{i}][\mathrm{k}] *$ forcetime1[i]); 
ct1005:

forall ( $\mathrm{k}$ in station)

taskduration2[k]==sum(i in task)(x[i][k]*forcetime2[i]);

ct5:

forall ( $\mathrm{k}$ in station)

sum(i in task)accelerationx[i]*vibrationtime $[\mathrm{i}] * x[\mathrm{i}][\mathrm{k}] * 8 * 3600 / \mathrm{c}==$ tempxd[k]*3600;

ct6:

forall ( $\mathrm{k}$ in station)

$\operatorname{sum}(\mathrm{i}$ in task $)\left(8^{*}\right.$ vibrationtime[i]*x[i][k]/c)==tempxe[k];

ct7:

forall ( $\mathrm{k}$ in station)

tempxN1[k]==piecewise $\{144->1 ; 64$-> 2;36 -> 4;16\}tempxe[k];

ct8:

forall ( $\mathrm{k}$ in station)

tempxN2[k]==piecewise $\{0$-> 1;80 -> 1;0 -> 2;56 -> 2;0 -> 4;80 -> 4;0\}tempxe[k];

ct9:

forall ( $\mathrm{k}$ in station) 
vibrationlimitx $[\mathrm{k}]==$ tempxN1[k]-tempxN2[k];

ct910:

forall ( $\mathrm{k}$ in station)

tempxd[k]<=vibrationlimitx $[\mathrm{k}]$;

ct911:

forall ( $\mathrm{k}$ in station)

sum(i in task)accelerationy[i]*vibrationtime $[\mathrm{i}] * x[\mathrm{i}][\mathrm{k}] * 8 / \mathrm{c}==$ tempyd $[\mathrm{k}]$;

ct912:

forall ( $\mathrm{k}$ in station)

$\operatorname{sum}(\mathrm{i}$ in task $)\left(8^{*}\right.$ vibrationtime[i]*x[i][k]/c)==tempye $[\mathrm{k}]$

ct913:

forall ( $\mathrm{k}$ in station)

tempyN1[k]==piecewise $\{144$-> 1;64 -> 2;36 -> 4;16\}tempye[k];

ct914:

forall ( $\mathrm{k}$ in station)

tempyN2[k]==piecewise $\{0$-> 1;80 -> 1;0 -> 2;56 -> 2;0 -> 4;80 -> 4;0\}tempye[k]; ct915: 
forall ( $\mathrm{k}$ in station)

vibrationlimity $[\mathrm{k}]==$ tempyN1[k]-tempyN2[k];

ct916:

forall ( $\mathrm{k}$ in station)

tempyd $[\mathrm{k}]<=$ vibrationlimity $[\mathrm{k}]$;

ct917:

forall ( $\mathrm{k}$ in station)

sum(i in task)accelerationz[i]*vibrationtime[i]*x[i][k]*8/c==tempzd[k];

ct918:

forall ( $\mathrm{k}$ in station)

$\operatorname{sum}(\mathrm{i}$ in task $)\left(8^{*}\right.$ vibrationtime $\left.[\mathrm{i}] * \mathrm{x}[\mathrm{i}][\mathrm{k}] / \mathrm{c}\right)==$ tempze $[\mathrm{k}]$;

ct19:

forall ( $\mathrm{k}$ in station)

tempzN1[k]==piecewise $\{144$-> 1;64 -> 2;36 -> 4;16\}tempze[k];

ct20:

forall ( $\mathrm{k}$ in station)

tempzN2[k]==piecewise $\{0$-> 1;80 -> 1;0 -> 2;56 -> 2;0 -> 4;80 -> 4;0\}tempze[k]; 
ct21:

forall ( $\mathrm{k}$ in station)

vibrationlimitz $[\mathrm{k}]==$ tempzN1[k]-tempzN2[k];

ct22:

forall ( $\mathrm{k}$ in station)

tempzd $[\mathrm{k}]<=$ vibrationlimitz $[\mathrm{k}]$;

\} 


\section{C4. Code-2 Data}

$\mathrm{N}=5$;

task = "f1", "f2", "f3", "f4","f5", "f6", "f7", "f8", "f9", "f10", "f11","f12","f13","f14","f15"\};

$\begin{array}{rrrrr}\text { tasktime }=\quad[9.3, & 23.8, & 3.6, & 12.7, & 11.1, \\ 30.9, & 17.1, & 16.7, & 18.9, & 11.5, \\ 14.3, & 10.3, & 15.4, & 18.6, & 0] ; \\ & & & & \end{array}$

taskpreced $=$

//F1 F2 F3 F4 F5 F6 F7 F8 F9 F10 F11 F12 F13 F14 F15

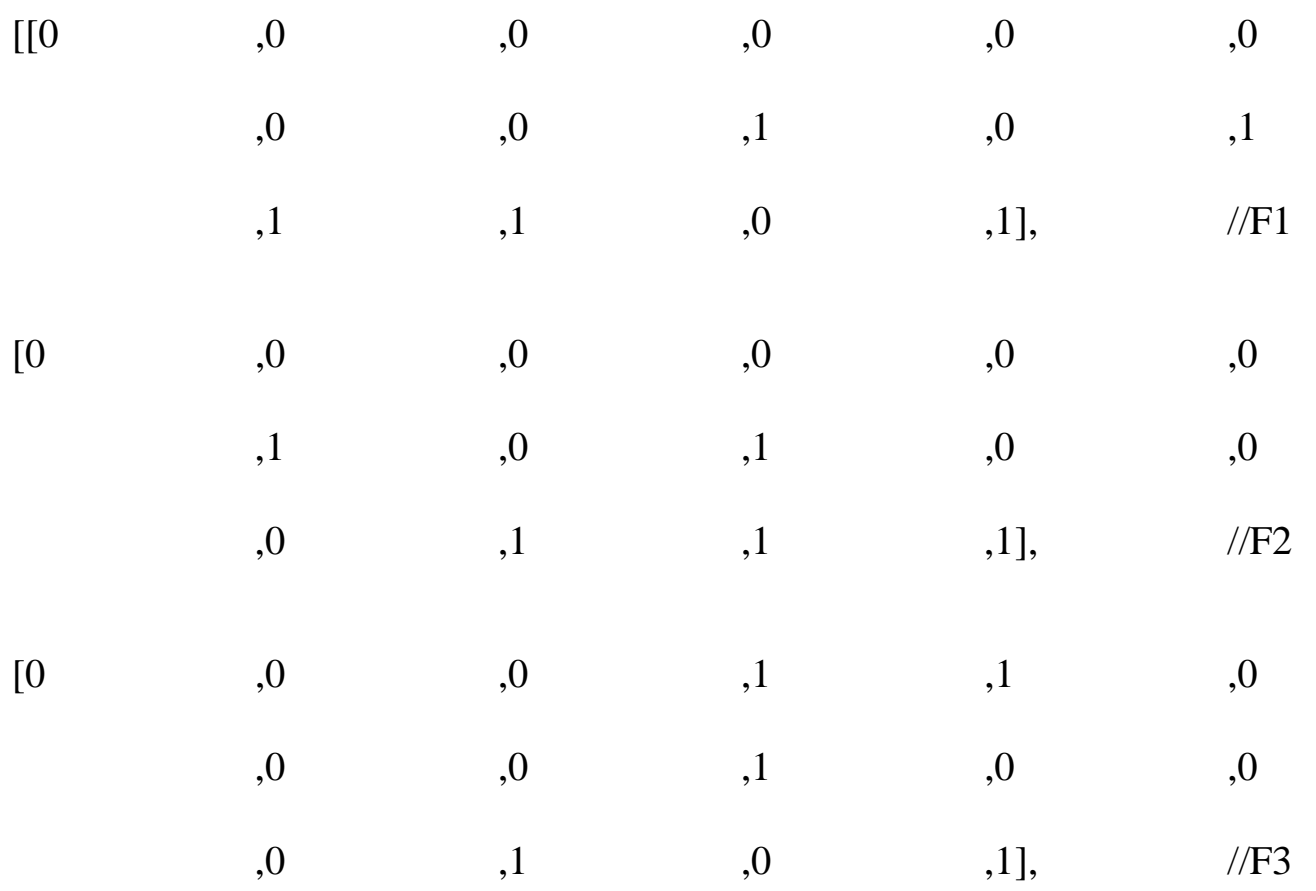


[0

,0

,0

,0

,1

,0

,0

,1

,0

,0

,0

,0

,1],

//F4

[0

,0

,0

,0

,0

,0

,0

,1

,0

,0

,0

,1

,1],

//F5

[0

,0

,0

,0

,0

,0

,0

,0

,1

, 0

,0

, 0

, 1

,1],

//F6

[0

,0

,0

,0

,0

,0

,0

,0

,1

,0

,0

,0

, 1

,1],

//F7

[0

,0

,0

,0

,0

,0

,0

,0

,1

,0

,0

,0

,1

,1],

//F8

[0

,0

,0

,0

,0

,0

,0

,0

,0

,0

,0

,0

,1

,1],

//F9

[0

,0

,0

,0

,0

,0

,0

,0

,0

,0

,0

,0

,1

,0

,1],

//F10 
[0

$\begin{array}{lllll}, 0 & , 0 & , 0 & , 0 & , 0 \\ , 0 & , 0 & , 0 & , 0 & , 0\end{array}$

,1

,0

,1],

//F11

[0

,0 , ,

,0

, 0

, 0

, 0

,0

,0

, 0

,0

, 0

,0

,1],

//F12

[0

,0

,0

, 0

,0

, 0

,0

, 0

,0

, 0

,0

,1],

//F13

[0

,0

,0

,0

, 0

,0

, 0

,0

,0

, 0

,0

, 0

,0

,0

$, 1]$

//F14

$[0$

$\begin{array}{ll}, 0 & , 0 \\ , 0 & , 0 \\ , 0 & , 0\end{array}$

,0

, 0

, 0

, 0

, 0

, 0

,0

,0

, 0

,0]];

//F15

// "f1", "f2", "f3", "f4","f5", "f6", "f7", "f8", "f9", "f10",

"f11","f12","f13","f14","f15",

\begin{tabular}{|c|c|c|c|c|c|}
\hline exertion1= & {$[3$,} & 6 & 2 & 3 & 3 \\
\hline & 3 & 5 & 4, & 6 & 2 \\
\hline & 3 & 3 & 3 , & 6 & 0]; \\
\hline
\end{tabular}




\begin{tabular}{|c|c|c|c|c|c|}
\hline \multirow[t]{3}{*}{ forcetime1= } & [ 5.8, & 7 & 2.2 & 8.3, & 6.7, \\
\hline & 3.3, & 11.4, & 9.1, & 4 & 7.4, \\
\hline & 10.3, & 1.8, & 5.5 & 5.7 & $0]$ \\
\hline \multirow[t]{3}{*}{ vforce1= } & {$[4.3$,} & 4.3, & 2.6, & 4.3, & 4.3, \\
\hline & 4.3, & 4.3, & 2.6 & 3.5 , & 4.3, \\
\hline & 4.3, & 1.7, & 4.3, & 4.3, & $0]$ \\
\hline \multirow[t]{3}{*}{ exertion2= } & {$[1$,} & 2 & 2 & 1 , & 3 \\
\hline & 3 & 5, & 4, & 1 , & 2 , \\
\hline & 3 & 3 & 3 & 6 & $0]$ \\
\hline \multirow[t]{3}{*}{ forcetime2= } & {$[1.8$,} & 1 , & 2.2 & 8.3, & 7 \\
\hline & 4.8, & 10 & 7.1, & 0.6, & 7 \\
\hline & 8.8, & 1.8, & 5 & 8, & $0]$ \\
\hline \multirow[t]{3}{*}{ vforce2= } & {$[2.8$} & 2.8 & 2.8 & 2.8 & 2.8, \\
\hline & 1.9, & 2.8 & 2.8 & 2.8, & 2.8, \\
\hline & 1.9, & 1.9, & 2.8 & 2.8 & 0]; \\
\hline
\end{tabular}

acceleration $x=[3.24,3.24, \quad 0,3.24,313.29,0,313.29,0,0,3.24,313.29$, 0, 313.29, 0, 0];

accelerationy $=[2.25,2.25,0,2.25,11.56,0,11.56,0,0,2.25, \quad 11.56$, $0, \quad 11.56,0,0]$ 


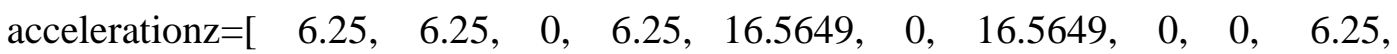
16.5649, 0, 16.5649, 0, 0];

$\begin{array}{rrrrr}\text { vibrationtime }=[5, & 4, & 0, & 3, & 2, \\ 0, & 4, & 0, & 0, & 7, \\ 2, & 0, & 3, & 0, & 0] \text {; }\end{array}$




\section{APPENDIX D}

\section{SOLUTION POOL}

Table D.1 Part of the solution pool calculated by Code- 2

\begin{tabular}{|c|c|c|c|}
\hline & worker 1 & worker 2 & worker 3 \\
\hline solution1 & 23467 & 1581114 & 9101213 \\
\hline solution2 & 23467 & 158111214 & 91013 \\
\hline solution3 & 23467 & 15214 & 89101213 \\
\hline solution4 & 23467 & 15111214 & 891013 \\
\hline solution5 & 2347 & 156111214 & 891013 \\
\hline solution6 & 2347 & 158111214 & 691013 \\
\hline solution7 & 234714 & 156811 & 9101213 \\
\hline solution8 & 23467 & 11112 & 589101213 \\
\hline solution9 & 23478 & 1611 & 5910121314 \\
\hline solution10 & 2347 & 16891114 & 5101213 \\
\hline solution11 & 234714 & 1681112 & 591013 \\
\hline solution12 & 234714 & 15681112 & 91013 \\
\hline
\end{tabular}

